Authors' Copy - “Elettore, E., Freddi, F., Latour, M., Rizzano, G. (2021) Design and analysis of a seismic resilient steel moment resisting frame equipped with damage-free self-centering column bases. Journal of Constructional Steel Research, $179: 106543$. https://doi.org/10.1016/j.jcsr.2021.106543"

\title{
DESIGN AND ANALYSIS OF A SEISMIC RESILIENT STEEL MOMENT RESISTING FRAME EQUIPPED WITH DAMAGE-FREE SELF-CENTERING COLUMN BASES
}

\author{
Elena Elettore ${ }^{1, *}$, Fabio Freddi ${ }^{2}$, Massimo Latour ${ }^{1}$, Gianvittorio Rizzano ${ }^{1}$ \\ ${ }^{1}$ Department of Civil Engineering, University of Salerno \\ ${ }^{2}$ Department of Civil, Environmental and Geomatic Engineering, University College London \\ ${ }^{*}$ Corresponding Author. Tel.: +39 3276933946; E-mail address: eelettore@ unisa.it
}

\begin{abstract}
Many recent research studies focused on the development of innovative seismic resilient structures by chasing the objectives of minimising both seismic damage and repair time, hence allowing the definition of structures able to go back to the undamaged, fully functional condition, in a short time. In this context, the present study investigates an innovative type of self-centring damage-free steel column base (CB) connection and its beneficial effects when used within steel moment-resisting frames (MRFs). The proposed connection consists of a rocking column equipped with a combination of friction devices, providing energy dissipation capacity, and post-tensioned bars with disk springs, introducing restoring forces in the joint. Contrary to conventional steel CBs, the proposed connection exhibits moment-rotation behaviours that can be described by simple analytical equations, allowing the definition of an easy-to-apply design procedure. Numerical models of the connection, developed in OpenSees, are validated against experimental results and successively implemented within a four-storey case study steel MRF. Incremental Dynamic Analyses are performed to derive the samples of the demand for the engineering demand parameters of interest while accounting for the record-to-record variability. Fragility Curves show the effectiveness of the proposed solution in reducing the residual storey drifts and in protecting the first-storey columns from damage, hence providing significant advantages in terms of repairability, and hence resilience of the structure with a negligible increase on the overall cost. The results show that the damage-free behaviour of the CBs is a key requirement when self-centring of MRFs is a design objective.
\end{abstract}

KEYWORDS: Moment Resisting Steel Frames, Self-Centering, Damage-Free Column Bases, Structural Resilience, Seismic Design, Residual Drifts.

\section{INTRODUCTION}

According to modern seismic design codes [1-3], structures must be designed to remain elastic or only slightly damaged in case of frequent (low intensity) seismic events (i.e., Damage Limit State). Conversely, in case of rare (high intensity) seismic events (i.e., Ultimate Limit State), extensive damage is generally accepted. For this latter case, structures are typically designed to concentrate the seismic damage into dissipative fuses, whose ductility and energy dissipation capacity must be properly designed through the adoption of specific detailing rules. At the same time, global ductility is achieved through capacity design rules with the aim of avoiding non-ductile local failures, thus allowing the development of a high number of dissipative zones before the occurrence of global collapse. In steel Moment Resisting Frames (MRFs), this strategy results in over-strengthened columns and connections leading to structures characterised by weak beams and column bases (CBs), with full-strength joints [e.g., 4-7]. This approach, if on the one hand allows the achievement of the safety requirements, on the other hand, leads to significant damage of the structural components and large residual drifts which can significantly compromise the building reparability. This leads to high direct (i.e., repair costs) and indirect (i.e., business interruption) losses, which, in many cases, are not acceptable from both the social and economic perspective.

To overcome these drawbacks, in the last decades, many research studies focused on the development of innovative structural systems, where the seismic damage is limited to easy to replace, or repair, dissipative fuses, promoting structural resilience. Some examples are the use of seismic isolation systems, of supplemental damping devices and innovative rocking damage-free structures [e.g., 8, 9]. Within this framework, in steel MRFs, a widely investigated strategy consists in replacing the conventional full-strength beam-to-column connections with dissipative partial-strength joints where yielding or friction devices (FDs) represent the weakest part of the connection. This approach allows a significant improvement of the structure reparability while not affecting its seismic performance. Grigorian and Popov (1993) [10] pioneered the first FD to be included in beam-to-column connections and successively, many research studies, as well as practical applications, were carried out investigating and developing the so-called Sliding Hinge Joint (SHJ) [11]. This is an asymmetric friction beam-to-column connection, including a supplemental energy dissipation system where the top flange of the beam is fixed to a plate from the column, while a bottom flange plate and a web plate with elongated holes permit sliding of a friction interface. A similar low-damage joint typology, based on symmetric friction dampers, has been recently proposed for applications in steel MRFs $[12,13]$ and both systems have been extensively investigated.

It has been demonstrated that, although the use of beam-to-column connections equipped with FDs can be an efficient solution to protect the frame components from damage, it does not allow the control of the residual drifts. In fact, even though the use of FDs allows a significant improvement of the reparability, the occurrence of large residual drifts may still impair the building reparability after the occurrence of a severe seismic event [14]. Possible solutions to this issue have been proposed by several researchers and are based on the introduction of elastic restoring forces. Restoring forces 
are usually provided by the use of post-tensioned (PT) bars [e.g., 15-18] allowing the control of the rocking mechanisms, or by the use of self-centring bracing systems [e.g.,19, 20].

However, while large attention has been given to the definition of innovative, both dissipative and self-centring, beamto-column connections, additional studies are required for the definition of new solutions for low-damage self-centring CBs. These represent fundamental components of the structural system, and they must be protected from damage to achieve structural resilience. According to modern seismic design strategies, like those implemented within current international building codes [1], CBs can be conventionally designed as full- or partial-strength. Both approaches are characterised by significant drawbacks. The first one typically leads to the development of plastic hinges in the bottom end of the first storey columns, thus causing significant structural damage and residual drifts after a severe seismic event. The second one needs the knowledge of the complex hysteretic behaviour of the column base under cyclic loadings, which is difficult to predict [21-22] and hence this strategy is rarely followed.

In order to overcome these drawbacks, several alternative solutions have been proposed. Most of the strategies investigated to date are based on the use of rocking column connections, characterised by a combination of steel bars (e.g., PT bars, threaded rods, yield bolts) and specific energy dissipating devices [23-29]. The results showed the advantages of the systems in terms of improved self-centring capability. However, several drawbacks were also highlighted, including stress concentration with consequent damage at the onset of rocking, low energy dissipation capacity, pinching behaviour during unloading, and undesirable column axial shortening.

Additionally, other authors recently extended the idea of using FDs in CB joints. MacRae et al. (2009) [30] proposed two CB typologies based on the SHJ concept and Borzouie et al. (2015) [31] implemented several experimental works on different low-damage CB connections. These configurations allowed the achievement of superior behaviour under loading in the column strong-axis direction, while damage and stiffness degradation were observed under loading of the column in the weak-axis direction. Freddi et al. (2017) [32] presented and experimentally investigated [33] a rocking damage-free steel CB equipped with FDs and high-strength steel PT bars. Non-linear dynamic analyses were carried out showing the potential of the $\mathrm{CB}$ in preventing the first-floor column yielding and in eliminating residual deformations in steel MRFs. Amongst others, the main advances, with respect to other studies, were related to the use of a circular steel plate with rounded edges which was used as rocking base. The rounded edges prevented stress concentration and damage of the contact surfaces during the rocking, while the circular shape allowed rocking towards all plan directions. Similarly, Kamperidis et al. (2018) [34] proposed a partial strength low-damage self-centring steel CB equipped with PT tendons and hourglass shape steel yielding devices to dissipate the seismic energy. A similar approach was also followed by Wang et al. (2019) [35] while considering a concrete-filled square steel section as CB footing. These studies demonstrated the effectiveness of the proposed connections in providing both self-centring capabilities and damage-free behaviour. However, their complexity and the need for long PT bars could lead to high cost, thus limiting the application to some special structures.

Lately, Latour et al. (2019) [36] proposed and experimentally investigated an innovative rocking column splice connection where the seismic behaviour is controlled by a combination of friction devices, providing energy dissipation capacity, and PT bars with disk springs, introducing restoring forces. The experimental tests demonstrated the damagefree and self-centring capabilities of this innovative column connection. Concerning the configurations previously described, this connection is characterised by several advantages. Among others: 1) the self-centring capability is obtained with elements, i.e., PT bars and disk springs, which have a size comparable to the overall size of the column (e.g., long PT bars can be avoided); 2) the moment-rotation hysteretic behaviour of the components can be easily calibrated; 3) all the connection elements are moved far from the concrete foundation, avoiding any interaction with it.

The present study numerically investigates and compares the seismic performance of a conventional, seismically designed, steel MRF with full-strength $\mathrm{CB}$ connections and an equivalent steel MRF equipped with the innovative $\mathrm{CB}$ connections (MRF-CB) experimentally investigated in Latour et al. (2019) [36]. In both cases, the beam-to-column joints are conventional full-strength welded joints, and the design is performed following the Eurocodes. The study aims to evaluate the beneficial effects, i.e., self-centring capabilities and damage-free behaviour of the $\mathrm{CB}$, provided by the introduction of the innovative CB joints. A design procedure and a modelling strategy are defined for the CB connections and validated against experimental results considering the tests carried out by Latour et al. (2019) [36]. State-of-the-art numerical models are developed in OpenSees [37] for the frames, with and without the investigated CB connection, and non-linear time-history analyses are performed in an Incremental Dynamic Analyses (IDA) [38] fashion to evaluate their seismic response.

IDAs are carried out on a set of 30 ground motion records to account for the influence of the uncertainty related to the earthquake input, i.e., the record-to-record variability. The effects of model parameter uncertainty and epistemic uncertainty are less notable than the effects of record-to-record variability $[39,40]$ and hence they are not considered in this study. IDA allowed the definition of fragility curves [41] which provide the probability of exceeding a specified performance level, conditional to the ground motion shaking severity, quantified through an appropriately selected intensity measure (IM). In this context, fragility curves are used to evaluate the probability of exceedance of the value of residual interstorey drift limit of $0.5 \%$ which, for building frames, is conventionally associated to building reparability [42]. Additionally, several performance levels are considered by monitoring both global and local Engineering Demand Parameters (EDPs) and hence deriving both system and components-level fragility curves [44-45]. The comparison of the fragility curves shows how the introduction of the CBs significantly contributes to the reduction of the residual 
interstorey drifts for the seismic intensities of interests and to the protection of the first storey column from yielding, thus avoiding non-repairable damage of the columns, even under strong ground motions. Besides, they indicate how the introduction of the CBs does not produce any detrimental effect on the other structural components.

Fragility curves also provide information on the hierarchy of activation of the different mechanisms within the structure. It is worth mentioning that, while the use of self-centring CBs within an MRF also equipped with self-centring damage-free beam-to-column connections, investigated in Freddi et al. 2017 [32], is expected to produce a fully damagefree and self-centring structural system, the solution investigated in the present study has been identified as a compromise that could be easily applied in practice. In fact, the introduction of the proposed CB alone does not provide the damagefree behaviour to the beams but improves the self-centring behaviour of the whole system and protect the columns, which are difficult to repair or substitute, from damage. These represent huge advantages for the repairability and hence resilience of the structure. Additionally, the proposed CBs are easy to implement from a technological point of view and can be introduced with a negligible increase on the overall cost of the structure.

\section{SELF-CENTRING DAMAGE-FREE CB CONNECTION}

\subsection{Concept}

The column base connection investigated by Latour et al. (2019) [36] consists of a slotted column splice constituted by two parts equipped with FDs placed symmetrically to the web and flanges plus a system of PT bars with disk springs, located above a traditional full-strength base plate joint. The FDs assure additional seismic energy dissipation capacity while the PT bars promote the self-centring behaviour of the CB. The overall dimension of the connection is similar to the size of a traditional column splice, and it is characterised by the absence of interaction with the concrete foundation, as illustrated in Figure 1(a).

The friction devices consist of friction pads of thermally sprayed steel shims pre-stressed with high strength preloadable bolts, placed between the steel cover plates and the column. FDs are characterised by a rigid-plastic hysteretic model, which depends on the clamping force and the friction coefficient $\mu$ of the contact interfaces. In this way, the alternate slippage of the surfaces in contact, on which a transversal force is applied through high strength bolts, assures the seismic input energy dissipation capacity. Figure 1(b) shows the details of the web and flange friction pads, Figure 1(c) shows the details of the cover plates, while Figure 1(d) shows the oversized and slotted holes of the column's web and flange which are designed to accommodate the gap opening required to reach the target rotation.

Moreover, one or more high-strength PT bars with disk springs are symmetrically placed and connected to anchorage plates welded to the column, in order to increase the axial force and to control the rocking behaviour of the CB by providing restoring forces in the joint to return towards the initial straight position at the end of the seismic event. The disk springs, arranged in parallel and series act as a macro-spring system, ensuring sufficient deformability to the connection and an adaptable stiffness-resistance combination. The details of the PT bars and the disk spring systems are illustrated in Figure 1(e).

a) Disk spring

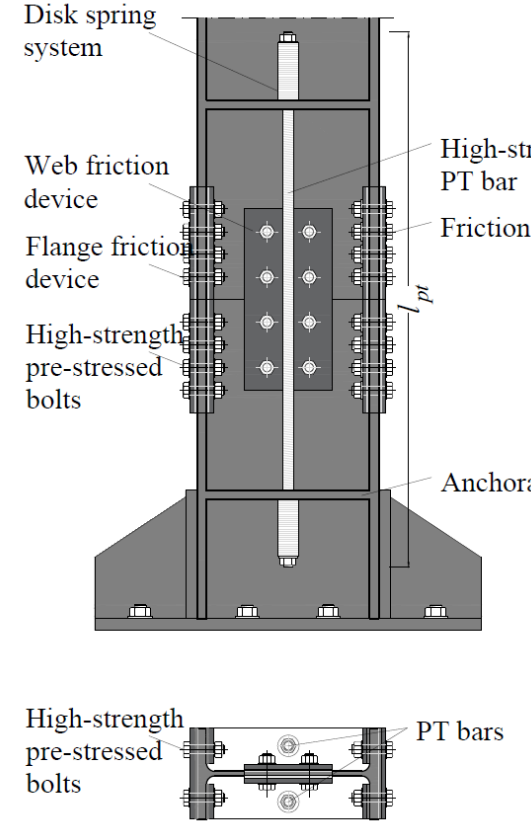

b)

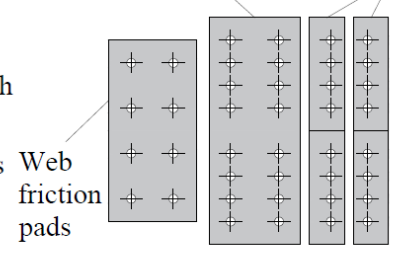

d)

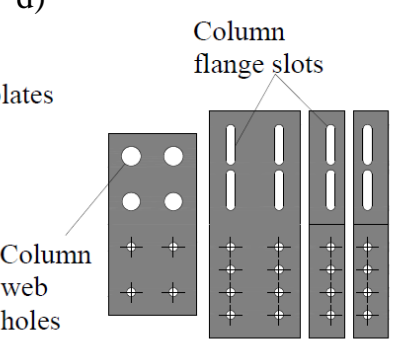

External flange Internal flange friction pads friction pads

c) Steel plates for the flange friction devices friction device

e)

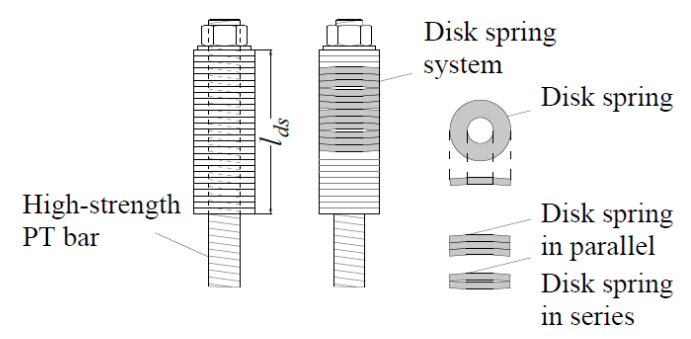

Figure 1- Column base connection: (a) Plan and elevation view; (b) web and flange friction pads;

(c) web and flange cover plates; (d) oversized and slotted holes of the column's web and flange; (e) disk springs system. 


\subsection{Moment-rotation behaviour}

The moment-rotation hysteretic behaviour of the components is simply obtained by the following steps. The expected forces in each component during the rocking behaviour can be represented by imposing static equilibrium at the centre of rotation $(\mathrm{COR})$, as reported in Figure 2(a). $\mathrm{F}_{\mathrm{c}}$ represents the compression force at the COR, $\mathrm{F}_{\mathrm{w}}$ and $\mathrm{F}_{\mathrm{f}}$ represent the sliding forces in the friction pads on the column web and flange respectively, while $\mathrm{F}_{\mathrm{PT}}$ is the sum of the forces provided by the PT bars with disk springs. $\mathrm{F}_{\mathrm{PT}}$ can be calculated by considering the sum of $\mathrm{F}_{\mathrm{PT}, 0}$, which is the initial post-tensioning forces, and $\Delta \mathrm{F}_{\mathrm{PT}}$, which represents the additional force consequent to the gap opening while rocking. The momentrotation behaviour of the $\mathrm{CB}$ connection is a function of the response of each component and can be represented by the flag-shape curve of Figure 2(b).

a)

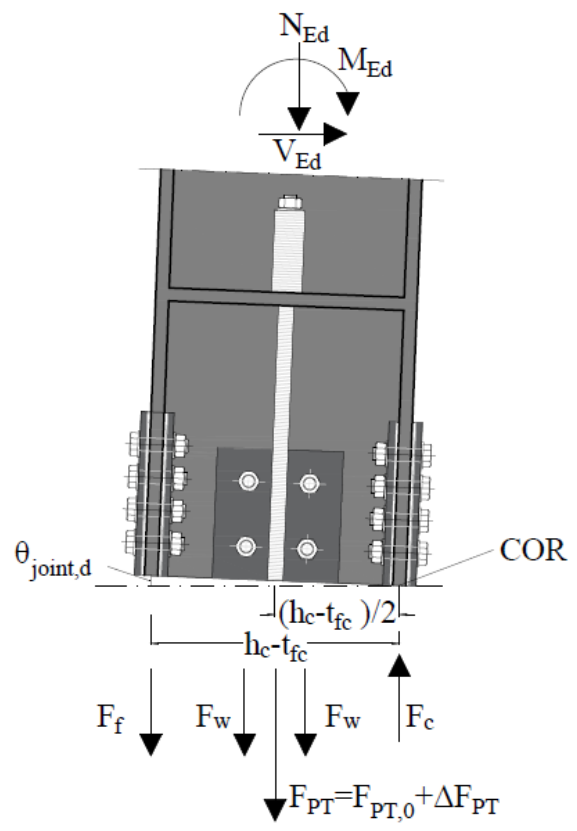

b)

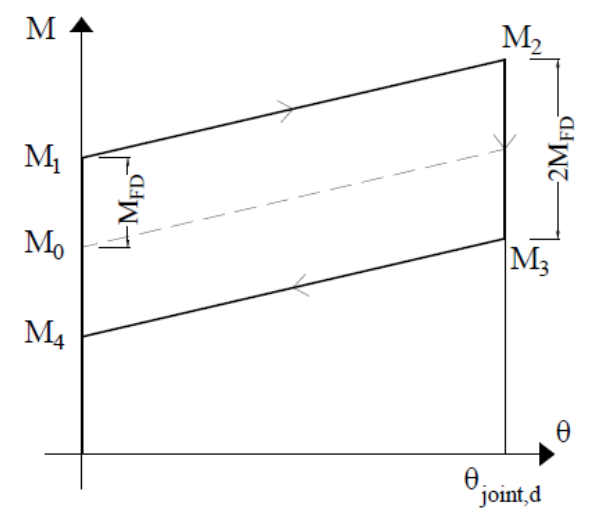

Figure 2-Column base connection: (a) Force interaction among the components during rocking; (b) Theoretical moment-rotation hysteretic curve.

The decompression moment $\mathrm{M}_{0}$ is given by the sum of the moment contributions related to the gravity loads directly applied on the structure plus the moment provided by the PT bars at zero rotation. $\mathrm{M}_{0}$ can be calculated as follows:

$$
\mathrm{M}_{0}=\left(\mathrm{N}_{\mathrm{Ed}}+\mathrm{F}_{\mathrm{PT}, 0}\right)\left(\frac{\mathrm{h}_{\mathrm{c}}-\mathrm{t}_{\mathrm{fc}}}{2}\right)
$$

where $\mathrm{N}_{\mathrm{Ed}}$ is the axial load applied to the joint section, $\mathrm{F}_{\mathrm{PT}, 0}$ is the initial post-tensioning forces of the PT bars, $\mathrm{h}_{\mathrm{c}}$ is the height of the column section and $t_{\mathrm{fc}}$ is the thickness of the column flange.

$\mathrm{M}_{\mathrm{FD}}$ represents the bending moment provided by the FDs and is given by:

$$
\mathrm{M}_{\mathrm{FD}}=\mathrm{F}_{\mathrm{f}}\left(\mathrm{h}_{\mathrm{c}}-\mathrm{t}_{\mathrm{fc}}\right)+2 \mathrm{~F}_{\mathrm{w}}\left(\frac{\mathrm{h}_{\mathrm{c}}-\mathrm{t}_{\mathrm{fc}}}{2}\right)
$$

where $F_{f}$ and $F_{w}$ represent the sliding forces in the friction pads of the column flanges and web, respectively.

$M_{1}$ is the moment that initiates the gap opening and is given by the sum of $M_{0}$ and $M_{F D}$ while $M_{2}$ is the maximum moment achieved at the design rotation $\theta_{\text {joint,d }}$. Its value is determined by accounting for the additional forces in the PT bars because of the gap opening:

$$
\mathrm{M}_{2}=\mathrm{M}_{0}+\mathrm{M}_{\mathrm{FD}}+\Delta \mathrm{M}_{\mathrm{PT}}
$$

where:

$$
\Delta \mathrm{M}_{\mathrm{PT}}=\Delta \mathrm{F}_{\mathrm{PT}}\left(\frac{\mathrm{h}_{\mathrm{c}}-\mathrm{t}_{\mathrm{fc}}}{2}\right)
$$

$$
\Delta \mathrm{F}_{\mathrm{PT}}=\mathrm{K}_{\mathrm{eq}} \theta_{\text {joint }}\left(\frac{\mathrm{h}_{\mathrm{c}}-\mathrm{t}_{\mathrm{fc}}}{2}\right)
$$


where $\mathrm{K}_{\mathrm{eq}}$ is the rotational stiffness of the system, which is a function of the stiffness of the PT bars and the stiffness of the disk spring system, as defined in the following part. It is important to stress that the maximum moment $\mathrm{M}_{2}$, must be lower than the yielding moment of the column $\left(\mathrm{M}_{\mathrm{pl}, \mathrm{c}}\right)$ to avoid plastic deformations.

$\mathrm{M}_{3}$ can be calculated as follows:

$$
\mathrm{M}_{3}=\mathrm{M}_{2}-2 \mathrm{M}_{\mathrm{FD}}
$$

Based on these equations, the self-centring behaviour of the connection is achieved if $\mathrm{M}_{4}>0$ and if the moment generated by the axial components $\left(\mathrm{M}_{0}\right)$, is higher than the moment provided by the FDs $\left(\mathrm{M}_{\mathrm{FD}}\right)$ :

$$
\mathrm{M}_{0} \geq \mathrm{M}_{\mathrm{FD}} \rightarrow \mathrm{F}_{\mathrm{PT}} \geq 2 \mathrm{~F}_{\mathrm{f}}+2 \mathrm{~F}_{\mathrm{w}}-\mathrm{N}_{\mathrm{Ed}}
$$

\subsection{Design procedure of the components}

The design actions, required for the design of the proposed self-centring $\mathrm{CB}$, are based on structural analysis of a conventional MRF with fixed base connections, considering the proper location of the column splices. The column axial load $\mathrm{N}_{\mathrm{Ed}}$ is assumed equal to the combination of the compression force due to gravity loads of the seismic load combination $\mathrm{N}_{\mathrm{Ed}, \mathrm{G}}$ and the axial load in the column due to the seismic design action $\mathrm{N}_{\mathrm{Ed}, \mathrm{E}}$, as required by Eurocode 8 [1]. The column bending moment $\mathrm{M}_{\mathrm{Ed}}$ is calculated considering the most unfavourable combination of axial forces (i.e., maximum compressive and maximum tensile force) and bending moment. In addition, $\mathrm{M}_{\mathrm{Ed}}$ is used for the design of the bolts in the web, which are assumed to carry alone the whole shear force. Successively, these bolts are further checked by considering $V_{E d}=M_{2} / L_{0}$, in order to ensure the capacity design against the shear mechanism, where $\mathrm{L}_{0}$ is the shear length of the column. Finally, in order to allow the gap opening, the web holes and flange slots are designed to accommodate a minimum rotation (e.g., 0.04 rads as suggested by AISC 341-16 [3] for Special Moment Frames). The positions of the holes are designed complying with the edge distances and spacing of bolts suggested by Eurocode 3 [46]. The necessary pre-load for the web FD is determined considering that the slippage force on the web is intended to resist the applied shear load as follows:

$$
\mathrm{F}_{\mathrm{w}}=\mu \cdot \mathrm{n}_{\mathrm{b}, \mathrm{w}} \cdot \mathrm{n}_{\mathrm{s}, \mathrm{w}} \cdot \mathrm{F}_{\mathrm{p}, \mathrm{w}} \geq \mathrm{V}_{\mathrm{Ed}}
$$

where $F_{w}$ is the slip resistance of the web friction dampers, $\mu$ is the design value of the friction coefficient, $\mathrm{n}_{\mathrm{b}, \mathrm{w}}$ is the number of web bolts and $n_{s, w}$ is the number of friction interfaces (equal to two, considering the symmetrical configuration) and $\mathrm{F}_{\mathrm{p}, \mathrm{w}}$ is the minimum pre-load force of each web bolt. Successively, imposing the system of equations between the self-centring condition of Eqn. (7) and the global equilibrium between the internal and external bending moment in correspondence of the splice, it is possible to obtain $\mathrm{F}_{\mathrm{PT}}$ and $\mathrm{F}_{\mathrm{f}}$, as follows:

$$
\left\{\begin{array}{c}
F_{P T} \geq 2 F_{f}+2 F_{w}-N_{E d} \\
F_{P T} \cdot\left(\frac{h_{c}-t_{f c}}{2}\right)+F_{f}\left(h_{c}-t_{f c}\right)=M_{E d}-\left(2 F_{w}+N_{E d}\right)\left(\frac{h_{c}-t_{f c}}{2}\right)
\end{array}\right.
$$

where $h_{c}$ is the column depth and $t_{f c}$ is the thickness of the column flange. The system of Eqn.s (9) leads to the following simple design formulation, which represents the minimum pre-load for the systems of the PT bars:

$$
\mathrm{F}_{\mathrm{PT}} \geq \frac{\mathrm{M}_{\mathrm{Ed}}}{\left(\mathrm{h}_{\mathrm{c}}-\mathrm{t}_{\mathrm{fc}}\right)}-\mathrm{N}_{\mathrm{Ed}}
$$

The pre-load for the flange FD is provided by the following expression:

$$
\begin{gathered}
\mathrm{F}_{\mathrm{f}}=\frac{\mathrm{M}_{\mathrm{Ed}}}{\left(\mathrm{h}_{\mathrm{c}}-\mathrm{t}_{\mathrm{fc}}\right)}-\frac{1}{2}\left(2 \mathrm{~F}_{\mathrm{w}}+\mathrm{N}_{\mathrm{Ed}}+\mathrm{F}_{\mathrm{PT}}\right) \\
\mathrm{F}_{\mathrm{f}}=\mu \cdot \mathrm{n}_{\mathrm{b}, \mathrm{f}} \cdot \mathrm{n}_{\mathrm{s}, \mathrm{f}} \cdot \mathrm{F}_{\mathrm{p}, \mathrm{f}}
\end{gathered}
$$

where $F_{f}$ is the slip resistance of the flange friction dampers, $\mu$ is the design value of the friction coefficient, $n_{b, f}$ is the number of web bolts and $\mathrm{n}_{\mathrm{s}, \mathrm{f}}$ is the number of friction interfaces (equal to two, considering the symmetrical configuration) and $F_{p, f}$ is the necessary pre-load force of each flange bolt. Finally, the disk springs system obtained by the arrangement of disk springs in series and in parallel provides the ideal stiffness-resistance combination to the $\mathrm{CB}$, and it is designed to be over-strength with respect to the PT bars. This latter condition is satisfied by the addition of the disks in parallel. Conversely, the number of disks in series is designed to avoid the PT bars yielding and the column yielding in 
correspondence of the maximum displacement of the farther PT bar with respect to the COR. The stiffness of the equivalent system, the PT bars and the disk spring system are defined as follows:

$$
\begin{aligned}
\mathrm{K}_{\mathrm{eq}} & =\frac{\mathrm{K}_{\mathrm{PT}} \mathrm{K}_{\mathrm{ds}}}{\mathrm{K}_{\mathrm{PT}}+\mathrm{K}_{\mathrm{ds}}} \\
\mathrm{K}_{\mathrm{PT}} & =\frac{\mathrm{n}_{\mathrm{b}} \mathrm{E}_{\mathrm{pt}} \mathrm{A}_{\mathrm{pt}}}{\mathrm{l}_{\mathrm{pt}}} \\
\mathrm{K}_{\mathrm{ds}} & =\frac{\mathrm{n}_{\mathrm{ds}, \mathrm{par}}}{\mathrm{n}_{\mathrm{ds}, \mathrm{ser}}} \mathrm{K}_{\mathrm{ds}, 1}
\end{aligned}
$$

where $\mathrm{n}_{\mathrm{b}}$ is the number of bars employed in the connection symmetrically placed with respect to the column centre, $\mathrm{l}_{\mathrm{pt}}$ is the bar length including the total length of the disk spring system $\left(\mathrm{l}_{\mathrm{ds}}\right), \mathrm{n}_{\mathrm{ds} \text {,par }}$ and $\mathrm{n}_{\mathrm{ds} \text {,ser }}$ are the number of disk springs in parallel and series respectively and $\mathrm{K}_{\mathrm{ds}, 1}$ is the stiffness of the single disk spring.

\subsection{Numerical Modelling and Validation}

A state-of-the-art two-dimensional finite element (FE) model for the CB connection is developed in OpenSees [37] and validated against the experimental results of Latour et al. (2019) [36]. Figure 3(a) shows the FE model of the proposed CB. The column is modelled with non-linear force-based fibre elements associated with the 'Steel01' material [37] for $355 \mathrm{MPa}$ yield strength and 0.02 post-yield stiffness ratio. The rigid elements of the rocking interface are modelled with elastic beam-column elements [37] with very high flexural stiffness. They are used to connect the lower and the upper part of the column through non-linear springs. These springs are represented by four bilinear zero-length elements in parallel with gap elements to simulate the bilinear hysteretic response of the FDs and the contact behaviour of the column interfaces. FDs for both flanges and web are modelled by the 'Steel01' material [37] considering a very high initial stiffness and very low post-elastic stiffness in order to model the rigid plastic behaviour of the FDs. Conversely, the contacts elements are defined by the 'Elastic compression-no tension' (ENT) material [37], which exhibits an elastic compression-no tension force-displacement behaviour. The compression stiffness of the contact spring is assumed as a very high value in order to model the contact behaviour. A central zero-length translational spring with bilinear elasticplastic behaviour is used to model the system of PT bars and disk springs. The initial post-tensioning force of the PT bars is modelled by imposing an initial strain equal to $\mathrm{F}_{\mathrm{PT}} / \mathrm{A}_{\mathrm{PT}} \mathrm{E}_{\mathrm{PT}}$ by using the 'Initial strain material' [37]. Furthermore, it is worth mentioning that the P-delta effects are not included in the simulations of these tests in order to properly capture the distribution of the forces according to the test setup.

a)

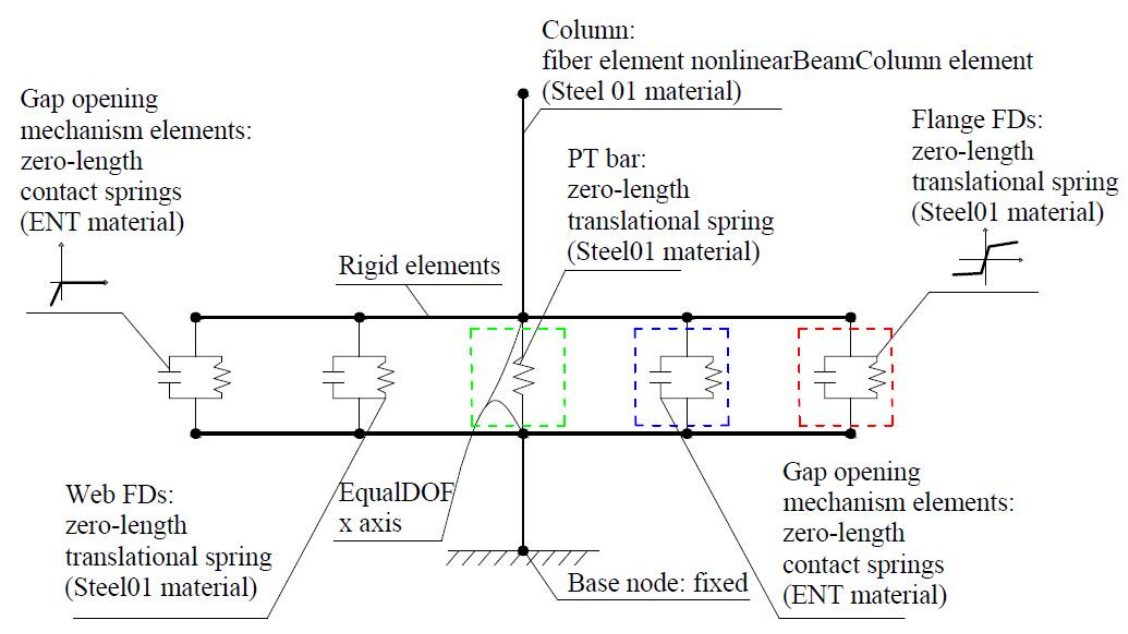

b)

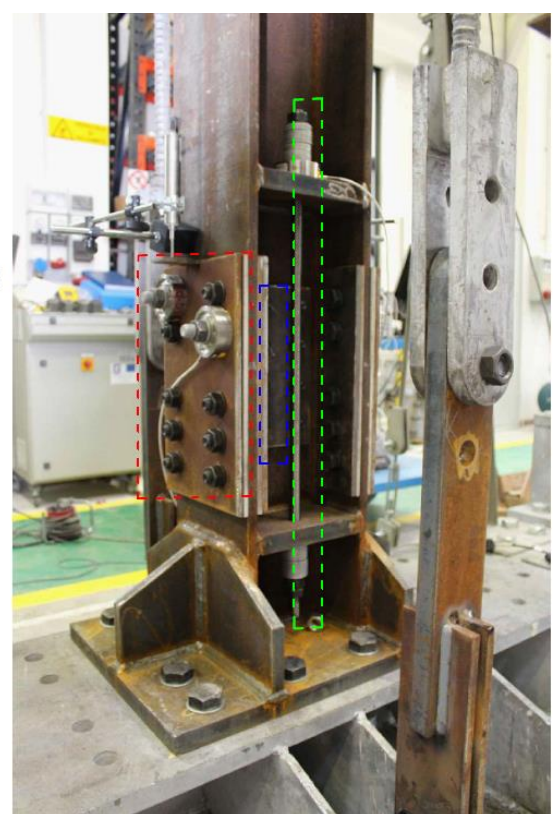

Figure 3- Column base connection: (a) 2D OpenSees [37] model; (b) Layout of the experimental tests [36].

The modelling strategy has been validated by comparing the numerical FE models in OpenSees [37] against the experimental results of the tests carried out by Latour et al. (2019) [36]. Several full-scale cyclic tests on the proposed damage-free self-centring rocking CB were performed at the Laboratory of Materials and Structures of the University of Salerno (Italy). The experimental campaign included several quasi-static cyclic and pseudo-dynamic tests performed on 


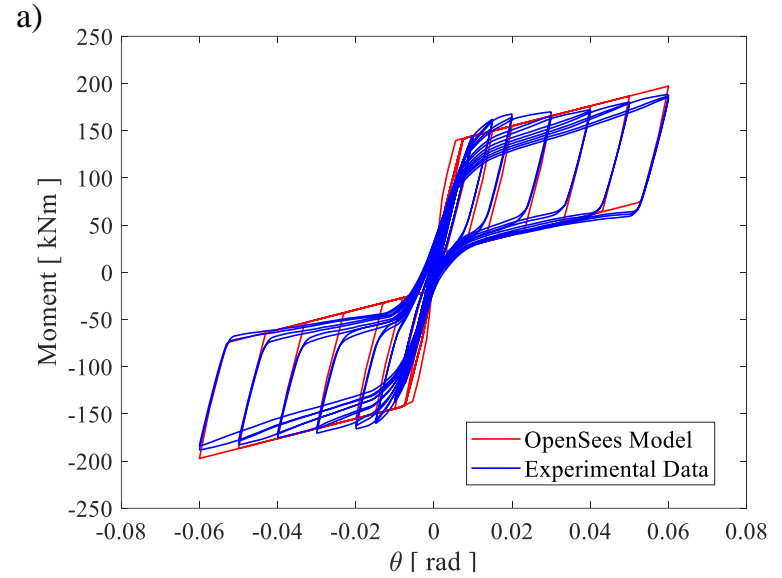
$20 \%$ with respect to the pre-loading experimental values.

a HE 240B specimen of S275 steel class, composed of two parts connected by S275 steel plates fastened by M20 HV bolts of 10.9 class to both web and flanges. The friction interface was characterised by previous tests which provided a friction coefficient $\mu=0.6$ [48]. Two M20 threaded bars with disk springs composed by three disks in parallel and seven disks in series have been adopted to control the self-centring behaviour. The loads in the quasi-static tests have been applied through two hydraulic jacks. One jack is used to apply the axial force, which is kept constant during the test. This assumption is not fully representative of a real situation in a steel MRF where, as a consequence of a seismic event, and especially for the external columns of the frame, a variation of the axial force is typically observed and not negligible. However, this assumption allowed the representation of the moment-rotation behaviour and an easier interpretation of the results. Besides, in order to simulate the cyclic load, a horizontal hydraulic jack is used to impose a horizontal displacements history with an increasing amplitude at each cycle. A detail of the specimen used in these tests is shown in Figure 3(b). Further information about these experimental tests is provided in [36].

In the present paper, numerical and experimental results are compared for four cyclic tests with different design parameters (i.e., the axial load in the column, the pre-loading force in the bolts of the FDs, the pre-loading force in the PT bars) as reported in Table 1. Hence, 4 FE models have been built in OpenSees [37] according to the modelling strategy previously described. The validation process allowed the investigation of the main parameters affecting the momentrotation hysteretic behaviour of the column connection. It is worth mentioning that, in order to account for pre-loading loss of the web and flange bolts during the experimental test [49] the web and flange pre-loading forces are reduced by

Table 1. Cyclic experimental Tests Data.

\begin{tabular}{ccccc}
\hline Test & $\begin{array}{c}\text { Axial load } \\
{[\mathrm{kN}]}\end{array}$ & $\begin{array}{c}\text { Pre-load of each web bolt } \\
{[\mathrm{kN}]}\end{array}$ & $\begin{array}{c}\text { Pre-load of each flange bolt } \\
{[\mathrm{kN}]}\end{array}$ & $\begin{array}{c}\text { Pre-load in each PT bar } \\
{[\mathrm{kN}]}\end{array}$ \\
\hline 1 & 728 & 32 & 62 & 100 \\
2 & 728 & 32 & 100 & - \\
3 & 350 & 32 & 100 & - \\
4 & 350 & 35 & 65 & 140 \\
\hline
\end{tabular}

c)

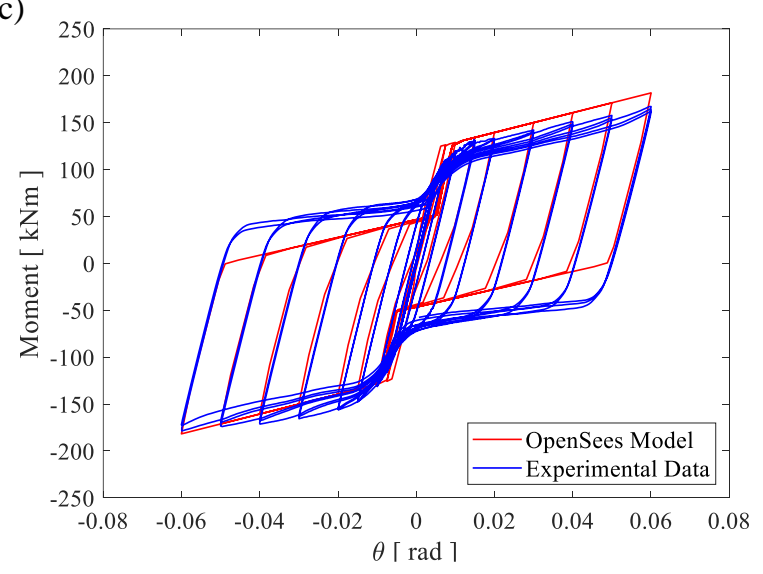

a)

b)

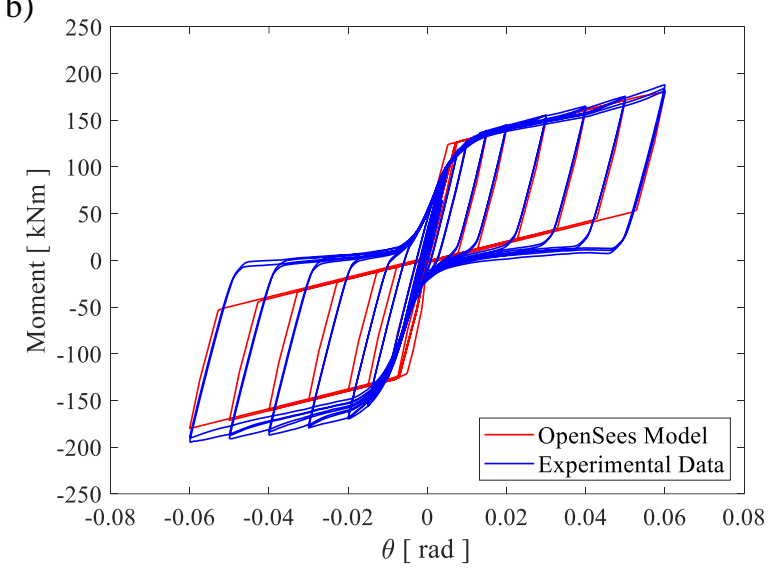

d)

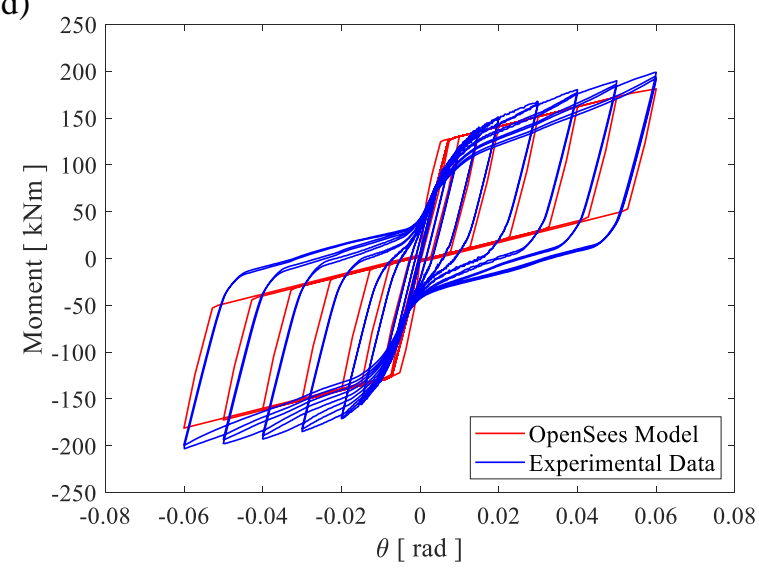

Figure 4-Moment-rotation behaviour of the column base connection. Comparison between OpenSees [37] and experimental results by Latour et al. (2019) [33] for the: (a) Test 1; (b) Test 2; (c) Test 3; (d) Test 4. 


\section{PERFORMANCE-BASED ASSESSMENT OF A CASE STUDY FRAME}

\subsection{Case-study frame}

In the following part of the paper, a case study MRF is designed, modelled, and numerically investigated in order to evaluate the influence of the proposed $\mathrm{CB}$ on the seismic response of the structure. Figure 5 shows the plan and the elevation view of the selected case-study frame, which has 4 storeys, 5 bays in -x direction and 3 bays in -y direction. The layout has interstorey heights of $3.20 \mathrm{~m}$ except for the first level, whose height is equal to $3.50 \mathrm{~m}$, while all the bays have spans of $6 \mathrm{~m}$. Seismic resistant perimeter MRFs are located in the -x direction and the y-direction while the interior part is composed of gravity frames (with pinned beam-to-column connections and pinned CBs). The study focuses on the assessment of the seismic resisting frames in the -x direction. Two configurations are analysed and compared: the first is a moment-resisting frame with full strength beam-to-column connections and conventional CBs (MRF); the second is an equivalent seismic resilient frame equipped with the innovative CB connections (MRF-CB) designed according to the procedure indicated in Section 2.3. In both cases, the beam-to-column joints are conventional full-strength welded joints, and the design is performed in accordance with the Eurocode 8 [1]. The steel-concrete composite floor system is composed of steel beams and HI BOND A55/P600 type composite floor connected through shear connectors to a concrete slab. The slab is supposed disconnected from the beam-to-column joints through the adoption of crushable material. The gravity and live loads are assumed as uniformly distributed with values respectively of $G_{k}=4.5 \mathrm{kN} / \mathrm{m}^{2}$ and $\mathrm{q}_{\mathrm{k}}=2 \mathrm{kN} / \mathrm{m}^{2}$. The gravity loads are transferred directly to the beams lying in the orthogonal direction due to the presence of a one-way slab. The total mass of the building is equal to 156.1 and 154.4 tons for the intermediate storey and the roof, respectively. The Type 1 elastic response spectrum with a peak ground acceleration equal to $0.35 \mathrm{~g}$ and soil type $\mathrm{C}$ is considered for the definition of the Design-Based Earthquake (i.e., DBE, probability of exceedance of $10 \%$ in 50 years, Ultimate Limit State according to the European definition). The Maximum Credible Earthquake (i.e., MCE, Collapse Limit State according to the European definition) is assumed to have an intensity equal to $150 \%$ the DBE. The behaviour factor is assumed equal to $\mathrm{q}=6.5$ in accordance with the requirements of the Eurocode 8 [1] for MRFs in DCH. The structure has non-structural elements fixed in a way so as not to interfere with structural deformations. Therefore, the interstorey drift limit for the Frequently Occurred Earthquake (i.e., FOE, probability of exceedance of $10 \%$ in 10 years, Damage State Limitation (DSL) according to the European definition) is assumed as 1\%, as suggested in the Eurocode 8 [1]. The steel yield strength is equal to $355 \mathrm{MPa}$ for the columns and $275 \mathrm{MPa}$ for beams. The frame is optimally designed to distribute a uniform ductility demand for all the storeys. The indication of beams and columns cross sections are reported in Table 2 . The panel zones are stiffened with doubler plates with a thickness equal to the one of the column web. This is essential to ensure adequate stiffness to the joints and to promote the plastic engagement of the beams only.

a)

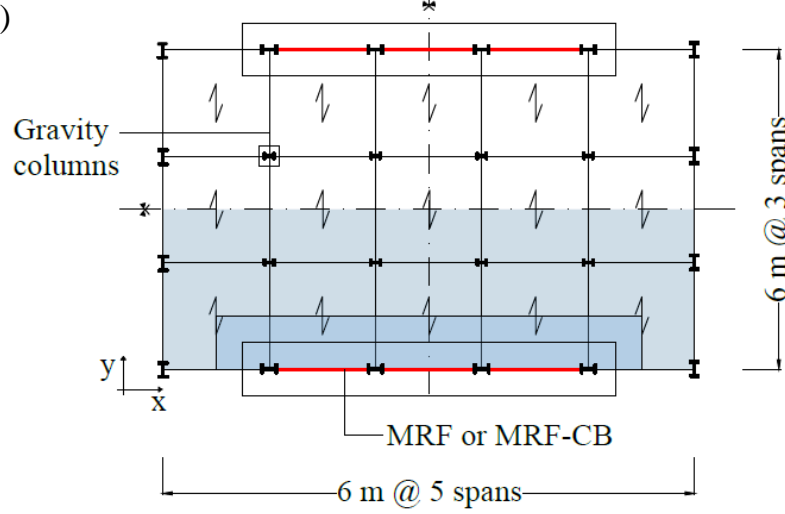

b)

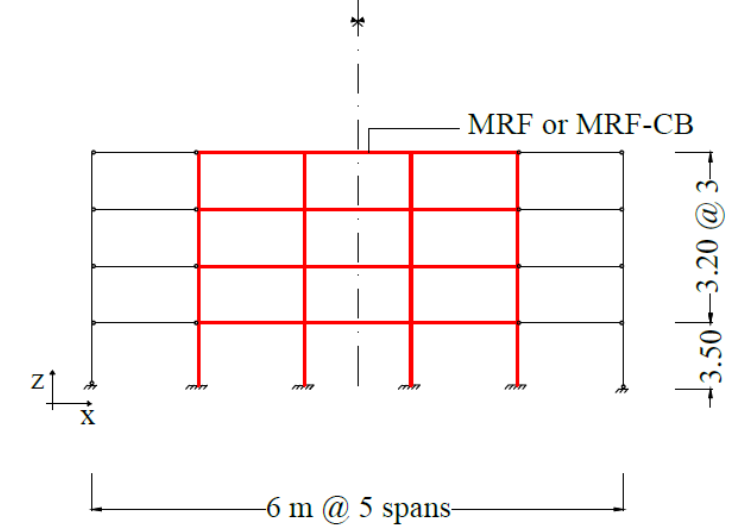

Tributary area for seismic mass

Triburary area for distributed loads

Figure 5-Case study building: (a) Plan view; (b) Elevation view.

Table 2. Profiles cross-sections.

\begin{tabular}{ccc}
\hline Floor & Columns & Beams \\
\hline 1 & HE 600B & IPE 550 \\
2 & HE 600B & IPE 550 \\
3 & HE 500B & IPE 500 \\
4 & HE 500B & IPE 500 \\
\hline
\end{tabular}




\subsection{Design of the column base (CB) connection}

a)

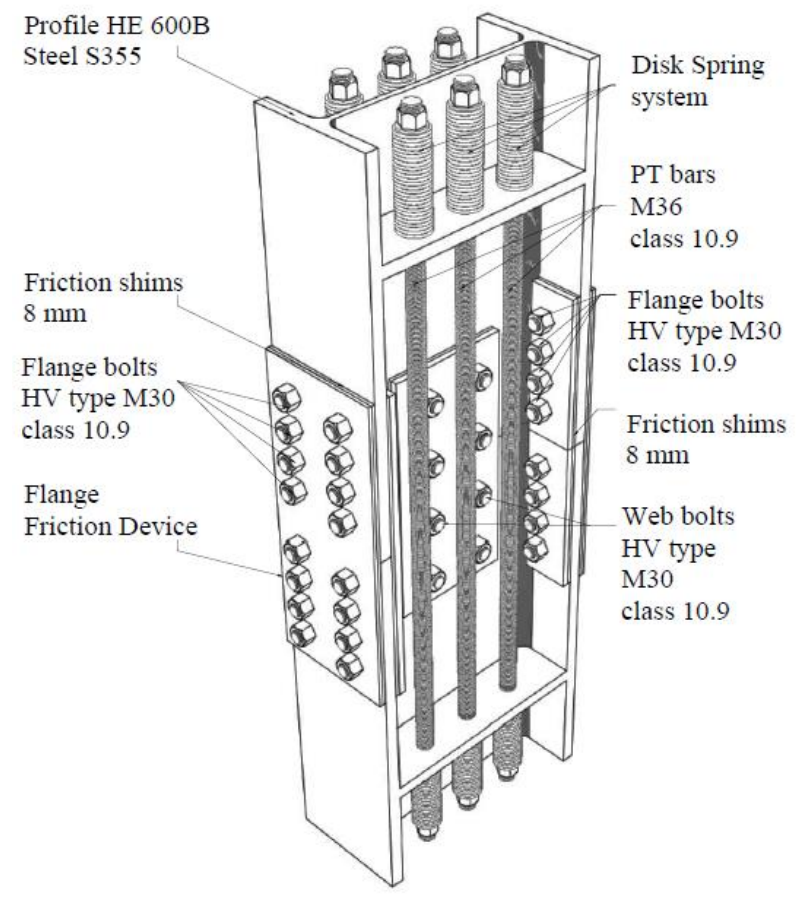

b)

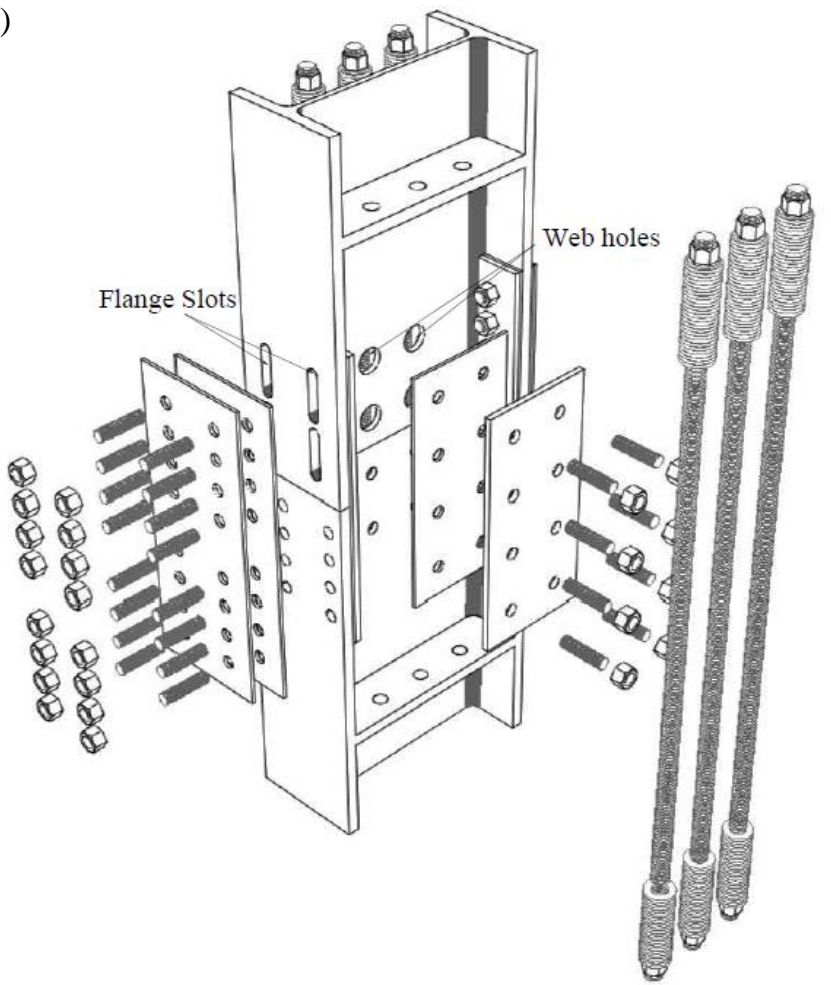

The CB connection is designed according to the procedure presented in Section 2. The design actions are derived based on the seismic analysis of the equivalent frame with rigid full-strength CBs and are defined considering the proper location of the column splices. For the inner columns, the maximum axial compressive force is equal to $460 \mathrm{kN}$, and its variation as a consequence of the seismic action is limited. In the outer columns, the axial tensile and compressive forces are equal to $807 \mathrm{kN}$ and $1240 \mathrm{kN}$, respectively. In this case, the tensile axial force is used for the design, while the CB is successively verified also with the max compressive force. The values of the design actions for the inner and outer columns are reported in Table 3.

\begin{tabular}{ccc}
\hline Design Actions & Inner columns & Outer columns \\
\hline Axial Load $\mathrm{N}_{\mathrm{Ed}}[\mathrm{kN}]$ & -460 & +807 and -1240 \\
Bending Moment $\mathrm{M}_{\mathrm{Ed}}[\mathrm{kNm}]$ & 1985 & 1633 \\
Shear Load $\mathrm{V}_{\mathrm{Ed}}[\mathrm{kN}]$ & 894 & 605 \\
\hline
\end{tabular}

Note: negative values are for compression; positive values are for tension.

Successively, the FDs, the PT bars and the disk spring system are designed. The friction pads are chosen according to the results of previous tests on friction material [48], and they consist of $8 \mathrm{~mm}$ of thermally sprayed friction metal steel shims. The friction coefficient is assumed equal to $\mu=0.53$. Considering four HV M30 10.9 class bolts for the web FD, the necessary pre-load for each bolt is $210 \mathrm{kN}$ and $140 \mathrm{kN}$ for the inner and outer columns respectively. Six M36 PT bars, having a maximum capacity of pre-loading of $570 \mathrm{kN}$ each, are introduced to control the self-centring behaviour. Considering eight HV M30 10.9 class bolts for the flange FD, the necessary pre-load for each bolt is $110 \mathrm{kN}$ and $60 \mathrm{kN}$, respectively for the inner and outer columns.

Figure 6-Structural details of the proposed column base connection: (a) 3D view; (b) Exploded 3D view.

The disk springs system is designed to provide the ideal stiffness-resistance combination to the system, as indicated in Section 2. The resistance of each disk spring is of $200 \mathrm{kN}$, while the stiffness $\left(\mathrm{K}_{\mathrm{ds} 1}\right)$ is of $100 \mathrm{kN} / \mathrm{mm}$. The overstrength of the disk spring with respect to the PT bars is satisfied by using a system of 3 disks in parallel. The number of disks in series relates to the stiffness of the equivalent system and is provided by the Eqn. (6). The maximum displacement of the farther PT bar with respect to the COR is equal to $17.4 \mathrm{~mm}(0.04 \times 435 \mathrm{~mm})$, where 0.04 rad is assumed as target rotation. Hence, a system of 18 disks in series is required to obtain the optimal stiffness of the whole system. Finally, web holes and flange slots are designed in order to accommodate drifts up to the target rotation. The positioning of holes for bolts is designed in accordance with the recommendations of the Eurocode 3 [46] for edge distances and spacings. Figure 6 (a) and (b) show a 3D and an exploded views of the proposed column base connection and the required components. 
The properties of the CB connections obtained by the design for the inner and outer column are summarised in Table 4, where $\mathrm{E}, \mathrm{f}_{\mathrm{y}}$ and $\mathrm{f}_{\mathrm{u}}$ are the nominal values of the Young's modulus, the yield strength and ultimate tensile strength of the materials, respectively. The other proprieties of the adopted structural steel (i.e., the shear modulus, the Poisson's ratio and the coefficient of linear thermal expansion) are based on the Eurocode 3 [47].

Table 4. Material properties.

\begin{tabular}{ccccccccc}
\hline & \multicolumn{3}{c}{ Material properties } & \multicolumn{2}{c}{ Outer column } & \multicolumn{2}{c}{ Inner column } \\
\hline Elements & $\begin{array}{c}\text { Class } \\
{[-]}\end{array}$ & $\begin{array}{c}\mathrm{E} \\
{[\mathrm{GPa}]}\end{array}$ & $\begin{array}{c}\mathrm{f}_{\mathrm{y}} \\
{[\mathrm{MPa}]}\end{array}$ & $\begin{array}{c}\mathrm{f}_{\mathrm{u}} \\
{[\mathrm{MPa}]}\end{array}$ & $\begin{array}{c}\text { Number } \\
{[-]}\end{array}$ & $\begin{array}{c}\text { Pre-load } \\
{[\mathrm{kN}]}\end{array}$ & $\begin{array}{c}\text { Number } \\
{[-]}\end{array}$ & $\begin{array}{c}\text { Pre-load } \\
{[\mathrm{kN}]}\end{array}$ \\
\hline Column and plates & $\mathrm{S} 355$ & 210 & 355 & 510 & - & - & - & - \\
Post-tensioned bars & 10.9 & 205 & 900 & 1000 & 8 & 570 & 6 & 570 \\
Web Bolts & 10.9 & 210 & 900 & 1000 & 4 & 140 & 4 & 210 \\
Flange Bolts & 10.9 & 210 & 900 & 1000 & 8 & 60 & 8 & 110 \\
\hline
\end{tabular}

\subsection{Frames modelling}

Two-dimensional FE models of the frames with and without the CB connections are developed in OpenSees [37]. The structural models are able to describe the non-linear response of the system by detailed modelling of the components. The 'Steel01' material [37] for $355 \mathrm{MPa}$ yield strength and $275 \mathrm{MPa}$ yield strength and $0.2 \%$ post-yield stiffness ratio is employed for columns and beams, respectively. Beams are modelled by a lumped plasticity approach where the internal part of the beams is modelled with elastic elements, while the plastic hinges are modelled by zero-length non-linear rotational springs at beams' ends. The rotational behaviour of these non-linear springs follows a bilinear hysteretic behaviour based on the modified Ibarra-Krawinkler deterioration rule implemented as suggested by Lignos and Krawinkler (2011) [50]. Conversely, in order to capture the axial force-bending moment interaction, columns are modelled by a distributed plasticity approach. Non-linear beam-column elements are used with four integration points, and each section is discretised into eight fibres along with the depth and four along each flange. The section aggregator function in OpenSees [37] is used in order to account for the shear stiffness of the column. At beam-to-column connections, the panel zone is modelled with the 'Scissor' model [51] where two rotational springs represent the shear behaviour of the panel zone and bending behaviour of the column flanges respectively. Geometric non-linearities are considered in the elements of the MRF. In addition, in order to consider the P- $\Delta$ effects related to the displacement and the axial forces in the gravity columns, an additional leaning column is included in the structural model [52]. This column is pinned at the base and continuous along the height of the building, and it is connected to the MRF by means of rigid trusses. The flexural and axial stiffness of the leaning column is equal to the sum of the flexural and axial stiffness of the gravity columns that it represents [52]. The rigid-floor diaphragm is modelled by assigning a high value to the axial stiffness to the beams. Gravity loads are applied on the beams by considering the seismic combination of the Eurocode 8 [1], while the masses are concentrated at the beam-to-column connections. Damping sources other than the hysteretic energy dissipation are modelled through the Rayleigh damping matrix where the values of the mass-related and stiffnessrelated damping coefficients are considered for a damping factor of $2 \%$ for the first two vibration modes. The fundamental period of vibration $\mathrm{T}_{1}=0.74 \mathrm{sec}$ is the same for both the structures.

\subsection{Pushover Analysis}

Non-linear static analyses with a distribution of lateral forces defined according to the first mode are performed on the MRF with conventional CBs and the same MRF including the proposed CBs. The results of these analyses are shown in Figure 7(a) and (b), which illustrate the storey shear versus the interstorey drift for each storey of the two structures. It is worth to stress out that, thanks to the design procedure, the structures are characterised by a homogeneous inelastic demand at all storeys. However, pushover results show that the first storey columns of the MRF with conventional CBs experiences damage and plastic deformations, while all the columns are fully protected from yielding in the MRF with the innovative CBs. It is also observed that in both the two structures, beams develop a similar level of damage in the plastic hinges.

Based on the results of the pushover analyses, structure-specific damage state thresholds, defined in terms of maximum interstorey drift, are mapped against local EDPs, as reported in Table 5. The use of global EDPs has several advantages and, amongst others, it synthetically describes the structural response containing the computational effort involved in the analysis of complex models. In this paper, the maximum interstorey drift $\left(\theta_{\mathrm{s}-\max }\right)$ is defined to describe the damage conditions at local-level considering specific member-level performances for both the structures (i.e., linear elastic limits of the components, yielding of the components, several inelastic deformation levels and ultimate chord rotation of the beams) and including also the behaviour of the CBs components (i.e., the sliding force of the FDs, ultimate chord rotation of the CB connections, yielding of the PT bars). For the beams, the inelastic deformation levels are expressed in terms of the plastic rotation as a multiple of the chord rotation at yielding $\left(\theta_{\mathrm{y}, \mathrm{b}}\right)$. It is worth mentioning that these plastic rotation levels are considered only to provide a comparison for the results of the two frames and do not have any correlation with 
conventional standardised damage levels. For the sake of brevity, the interstorey drifts limits corresponding to the member-level criteria are reported only for the first storey. However, the same performance level for local EDPs is reached for very similar values of interstorey drifts at the other storeys, as expected from the design. Figure 7(a) and (b) show the results of the pushover analyses in terms of storey shear versus interstorey drifts for the two structures, including the specific damage state thresholds.

Table 5-Maximum interstorey drifts thresholds mapping.

\begin{tabular}{cccc}
\hline EDPs & Performance levels & MRF & MRF-CB \\
\hline $\mathrm{M}_{\mathrm{el}, \mathrm{b}}$ & Limit of elastic behaviour in one beam & $4.6 \%$ o & $4.6 \%$ o \\
$\mathrm{M}_{\mathrm{pl}, \mathrm{b}}$ & Plastic moment in one beam & $5.3 \%$ o & $5.3 \%$ \\
\hline FDs & Sliding force of the friction devices & - & $6.8 \%$ o \\
$\mathrm{M}_{\mathrm{el}, \mathrm{c}}$ & Limit of elastic behaviour of one column & $7.0 \%$ o & - \\
$2 \theta_{\mathrm{y}, \mathrm{b}}$ & Beams performance levels & $1.3 \%$ & $1.3 \%$ \\
$4 \theta_{\mathrm{y}, \mathrm{b}}$ & measured as a multiplier of the & $2.7 \%$ & $2.7 \%$ \\
$\theta_{\mathrm{u}, \mathrm{b}}$ & chord rotation at yielding & $3.2 \%$ & $3.2 \%$ \\
$\mathrm{M}_{\mathrm{pl}, \mathrm{c}}$ & Ultimate chord rotation in one beam & $4.2 \%$ & - \\
$\theta_{\mathrm{u}, \mathrm{CB}}$ & Plastic moment in one column & - & $4.7 \%$ \\
$\mathrm{PT} \mathrm{bars}$ & Ultimate chord rotation $\theta_{\mathrm{u}, \mathrm{CB} \text { of the CB }}$ & - & $6.1 \%$ \\
\hline
\end{tabular}

a)

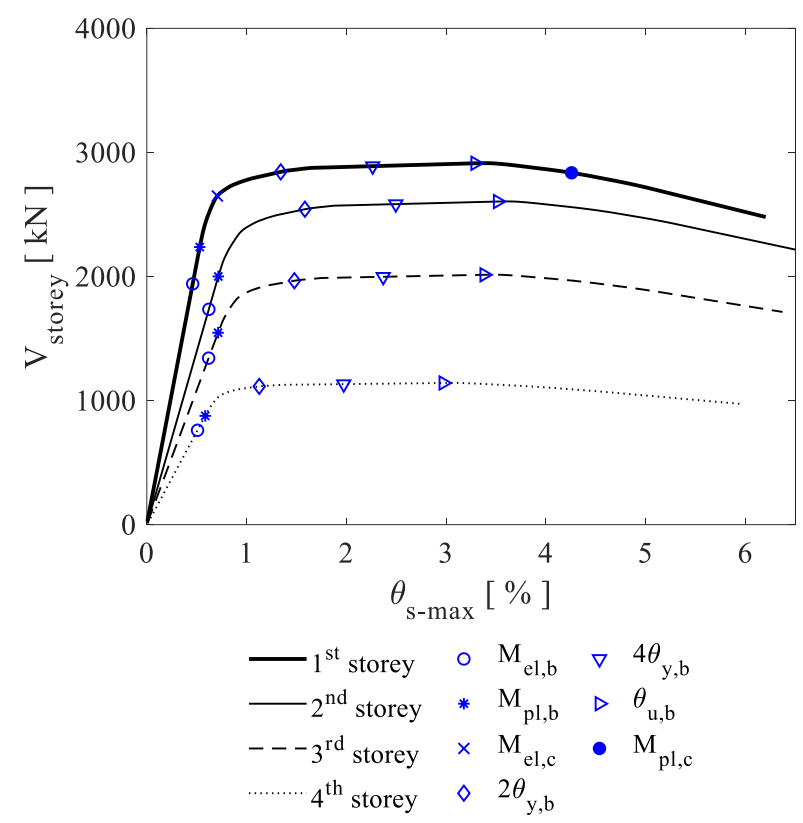

b)

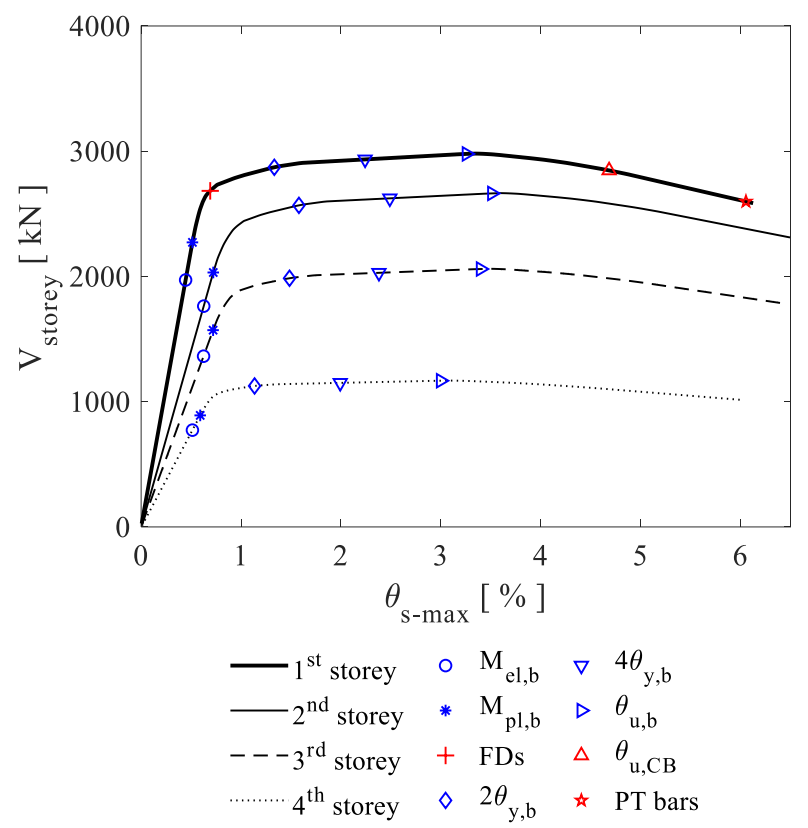

Figure 7- Storey shear vs. interstorey drift for: (a) the MRF; (b) the MRF-CB.

\subsection{Incremental Dynamic Analysis}

IDAs [38] are performed in order to investigate how the proposed CB influences the seismic response of the frame while also considering the influence of record-to-record variability. Non-linear time history analyses, for the MRF and MRF$\mathrm{CB}$, are performed by considering a suite of ground motion records scaled to increasing values of the IM to cover the whole range from elastic to non-linear seismic response of the frame up to collapse. The spectral acceleration corresponding to the first vibration mode $\left(\mathrm{S}_{\mathrm{a}}\left(\mathrm{T}_{1}\right)\right)$ is used as IM in the present study where $\mathrm{T}_{1}=0.74$ sec for both structures.

A set of 30 natural ground motions records is selected from the SIMBAD Database [53] with the following parameters: moment magnitude $\left(\mathrm{M}_{\mathrm{w}}\right)$ ranging from 6 to 7, epicentral distance $\mathrm{R} \leq 30 \mathrm{~km}$ and spectrum-compatibility in the range of periods between $0.2 \mathrm{~T}_{1}$ and $2 \mathrm{~T}_{1}$. The mean elastic spectrum of the records set is kept between $75 \%$ and $130 \%$ of the corresponding Eurocode based elastic response spectrum [1] expected at the site, as it is indicated in Figure 8. Therefore, global EDPs (i.e., residual interstorey drifts $\theta_{\mathrm{s} \text {-res }}$ and peak interstorey drifts $\theta_{\mathrm{s}-\mathrm{max}}$ ) are recorded allowing the comparison of the seismic performance of the two systems. The spectral acceleration $\left(S_{a}\left(T_{1}\right)\right)$ is equal to $0.98 \mathrm{~g}$ and $1.46 \mathrm{~g}$ respectively for the DBE and MCE which represent the two seismic intensities of interest. 


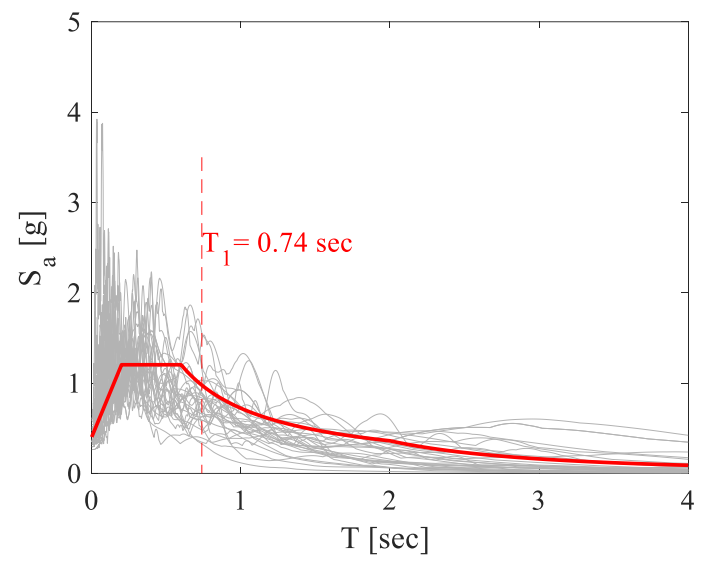

Figure 8-Spectra of the selected ground motion records [53].

Figures 9(a) and (b) illustrate the sample of the demand for the residual interstorey drifts $\theta_{\mathrm{s} \text {-res }}$ vs the IM for the first and the fourth storeys, respectively. For the sake of brevity, the results for the second and third storeys are not reported here. However, it is worth mentioning that they show a consistent trend in agreement with the first and the fourths storeys. It is worth highlighting that the introduction of the proposed CB allows a significant reduction of the residual interstorey drifts for both for the reported intensities (i.e., DBE and MCE). In particular, the MRF-CB experiences residual interstorey lower than $\theta_{\text {s-res-max }}=0.5 \%$ even for the MCE. This value is conventionally assumed as the threshold beyond which repairing the building may not be economically viable, as suggested by McCormick et al. (2008) [42]. Conversely, this limit is not satisfied at the MCE for the structure with full-strength CBs which experiences plastic deformations and damage. Similarly, Figures 10(a) and (b) show the samples of the demand for the peak interstorey drifts $\theta_{\mathrm{s} \text {-max }}$ vs the IM for the first and fourth storeys, respectively. It is noteworthy observing that the introduction of the proposed CBs does not affect the maximum response parameters of the structure. In fact, the two structures experience similar values of the maximum interstorey drifts at all the storeys. Moreover, it is also highlighted that the two structures achieve peak interstorey drifts $\theta_{\mathrm{s} \text {-max }}$ lower that $\theta_{\mathrm{s} \text {-FOE-max }}=1 \%$ under the FOE, as expected from the design [1]. Under this latter intensity, the higher values occur at the intermediate floors, where the peak interstorey drifts are close to the $1 \%$ limit.
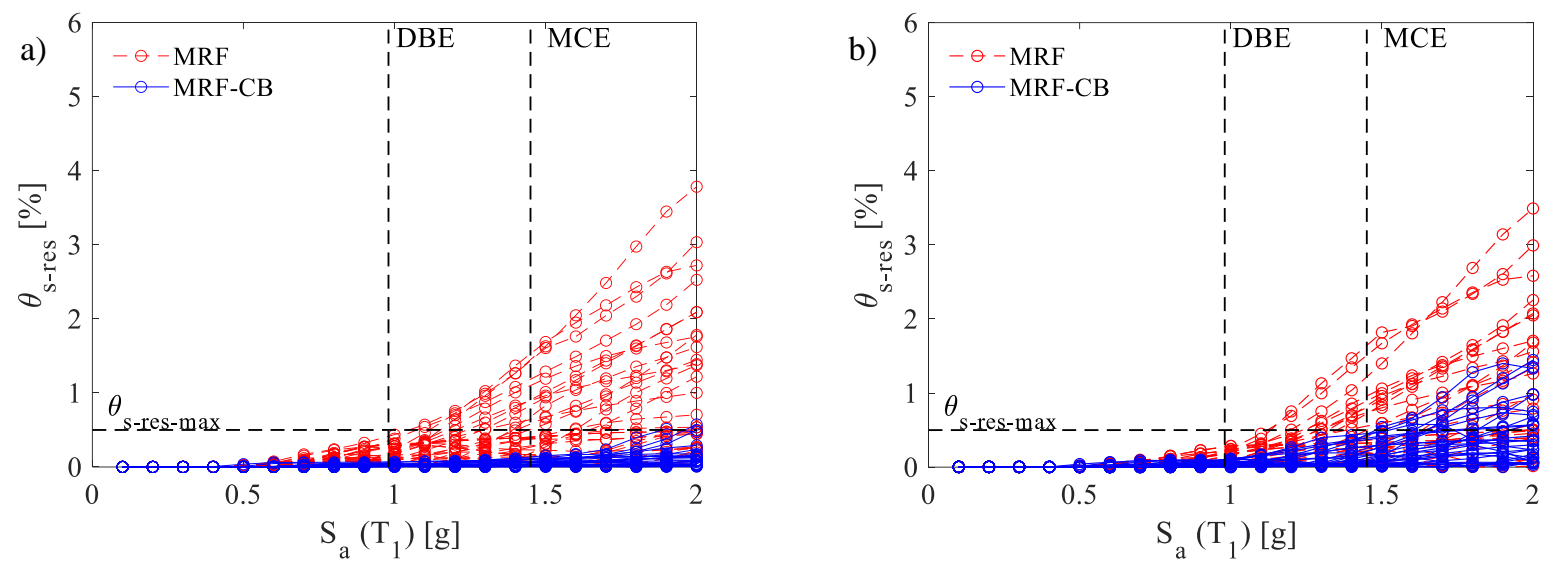

Figure 9-Comparison of the residual interstorey drift of the: (a) first storey and (b) fourth storey. 

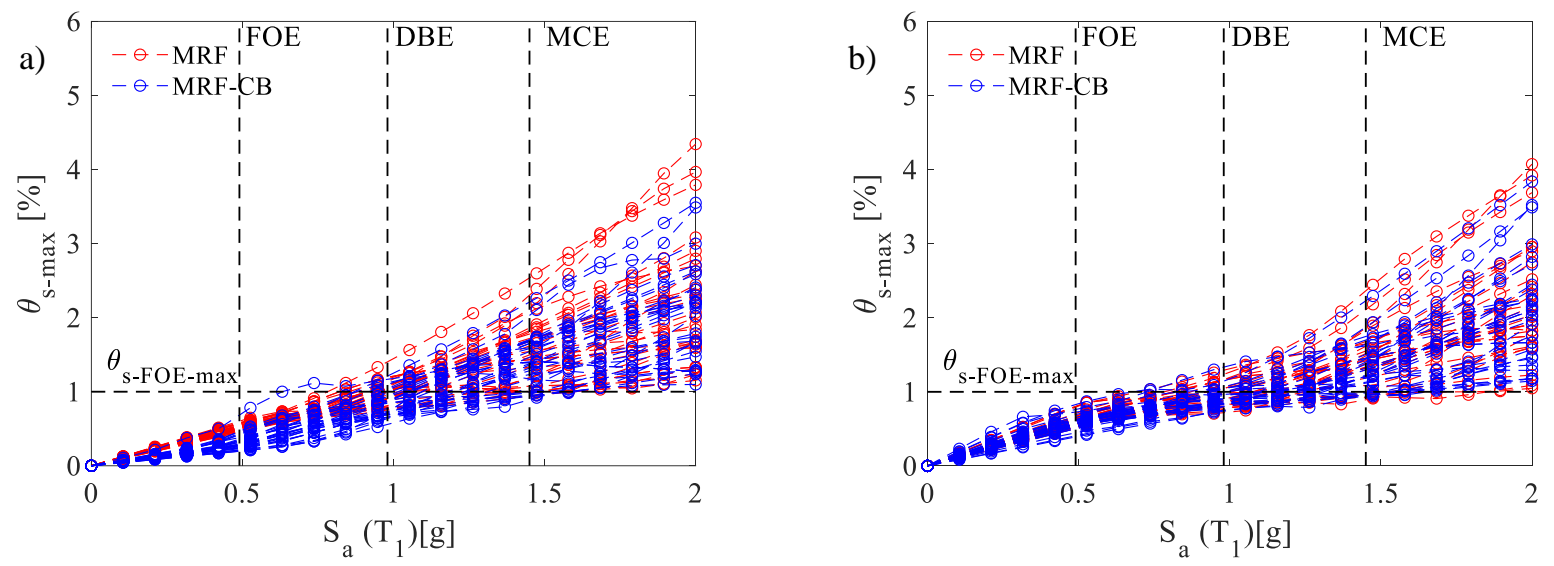

Figure 10-Comparison of peak interstorey drift of the: (a) first floor and (b) fourth floor.

The results summarised in Figure 9 and 10 can be observed for a single ground motion record, and for the two intensities of interest, in Figure 11 which shows the comparison of the first storey displacements history of the two frames. Figure 11 further highlights how the proposed CBs is able to minimise the residual drifts at the first storey of the MRF$\mathrm{CB}$ for both the DBE (Figure 11(a)) and the MCE (Figure 11(b)). In addition, the comparison of these displacements histories further highlights how the peak displacement response is similar for both the two structures.

Besides, the distribution of the residual interstorey drifts $\left(\theta_{\mathrm{s} \text {-res }}\right)$ at all the storeys is illustrated in Figures $12(\mathrm{a})$ and (b), respectively for the DBE and MCE intensities. Dotted lines represent the response of the single ground motions while the mean values are shown with solid lines. It can be observed that, despite the self-centring system is introduced only at the first storey, this also allows a reduction of the residual drifts at the higher storeys, with an efficiency that is decreasing along the height. This trend can be observed for both the seismic intensities of interest. Similarly, the distribution of peak interstorey drifts at all storeys is illustrated in Figure 13 for the two seismic intensities of interest. The results show that the maximum response parameters of the structure are not affected by the introduction of the CBs at any storey.
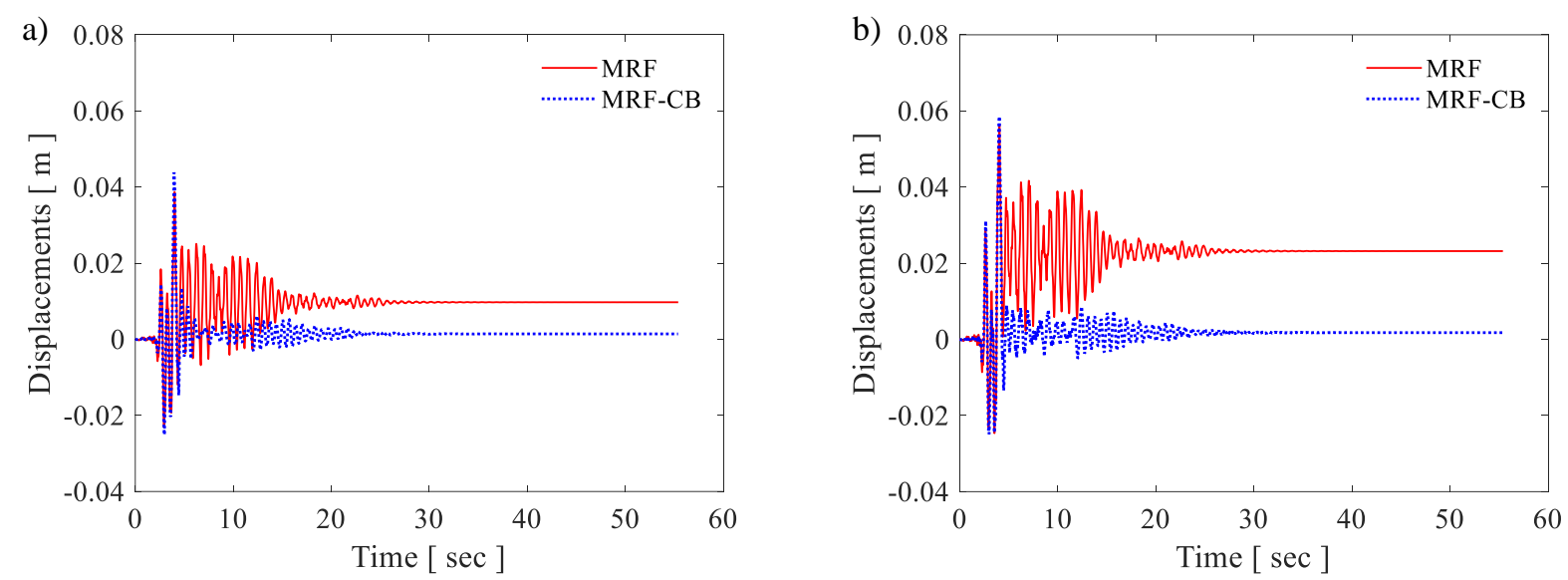

Figure 11-Comparison of the first storey displacement time history for a single ground motion record for: (a) DBE and (b) MCE intensities.

For a single ground motion record, Figure 14 compares the moment-curvature hysteretic behaviour of the bottom sections of the first storey columns of the two structures. Figure 14(a) shows how the MRF with conventional CBs experiences large plastic deformations and damage, thus leading to the need for repair measures after strong earthquakes. Figure 14(b) refers to the MRF-CB where the first storey columns experience a linear elastic behaviour and are fully protected from yielding under both the DBE and MCE. This is expected as due to the limitation imposed on the moment capacity of the connection during the design. Moreover, Figure 15 shows similar representations for beams' end where plastic hinges are developed. It can be observed that beams undergo similar plastic deformation and damage in both frames. This was expected based on the similar values of the peak interstorey drifts shown in Figure 13. Moreover, for both the structures, columns at higher storeys remain elastic, due to the capacity design rule enforced during the design [1], and panel zones remain within the elastic range, thanks to the introduction of the doubler plates. 
a)

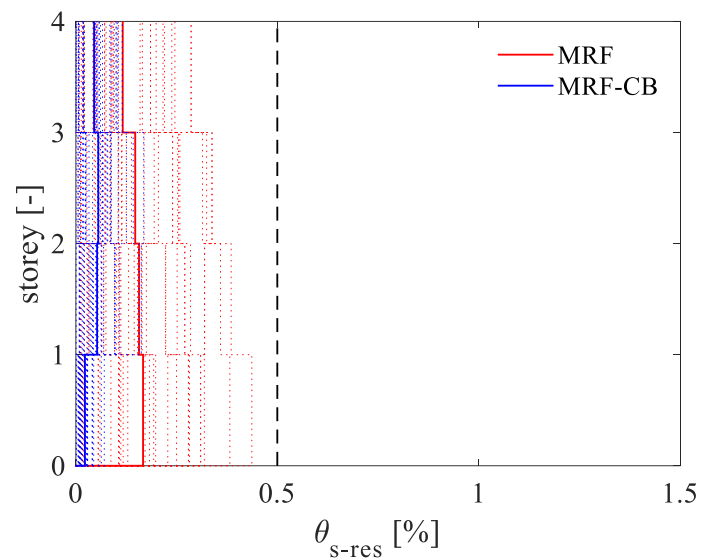

b)

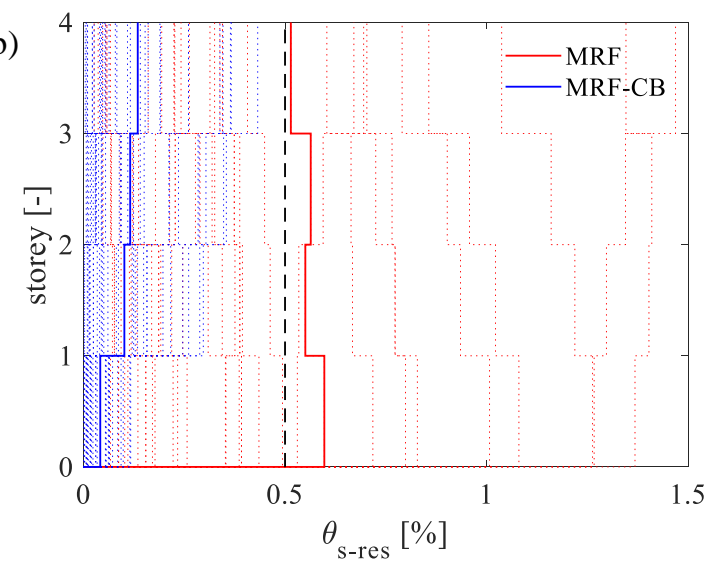

a)

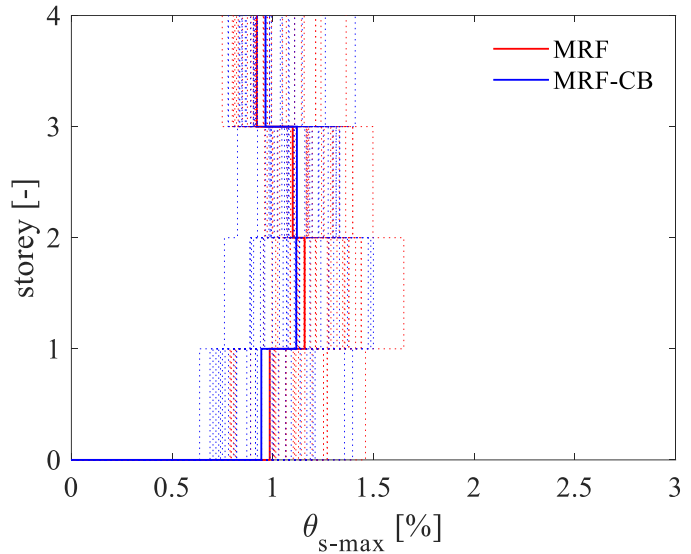

b)

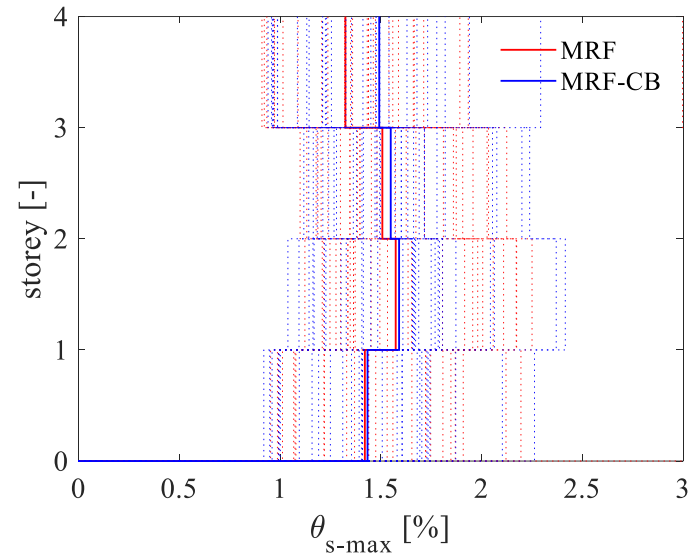

Figure 13-Comparison of the peak interstorey drifts distribution at all the storeys for the: (a) DBE and (b) MCE intensities.

a)

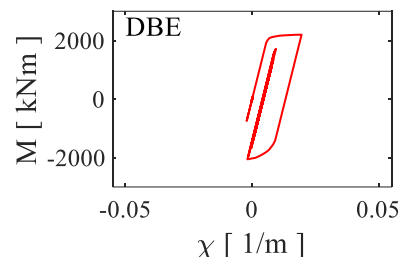

b)

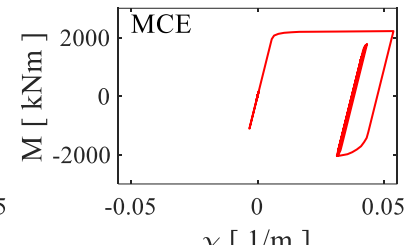

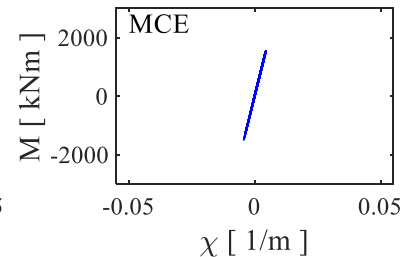

Figure 14-Moment-curvature relationship in the bottom section of one of the first storey columns of the: (a) MRF and (b) MRF-CB for a single ground motion record scaled at DBE and MCE.

a)

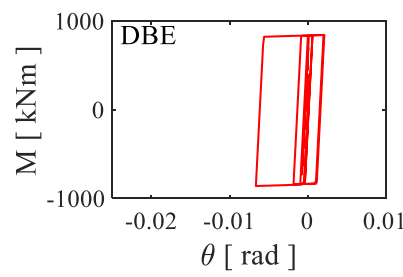

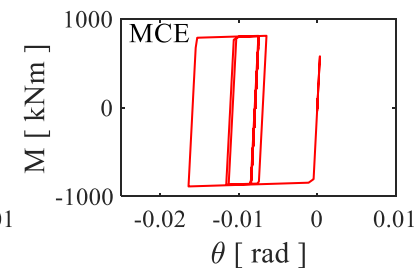

b)
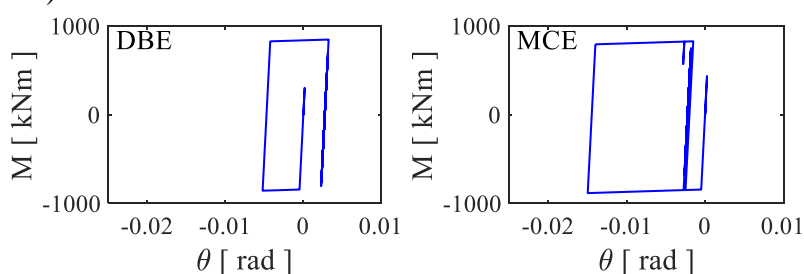

Figure 15-Moment-rotation relationship in the beam end of one of the first storey beams of the: (a) MRF and (b) MRF$\mathrm{CB}$ for a single ground motion record scaled at DBE and MCE. 


\subsection{Fragility curves}

Based on the results of the IDAs, fragility curves are derived numerically and successively fitted by analytical lognormal curves through least-square minimisation. The assumption of lognormality simplifies the analysis of the results and allows the synthetic description of the fragility of the systems by means of the two characteristic parameters describing the lognormal distribution.

Figure 16 shows the fragility curves related to the building repairability based on residual interstorey drifts. While the samples of the demand for this EDP are derived by the IDAs, the associated capacity threshold is assumed as $0.5 \%$. This value is conventionally assumed as the limit beyond which the repair of the building is not economically viable [42]. The comparison of the fragility curves is carried out for each storey of the two structures, demonstrating how the introduction of the CBs fully contributes to the reduction of the probability of failure at the first storey, while the effect decreases along the height, as it is highlighted in Table 6 . This result suggests that the use of a self-centring system localised only in the column bases of the building is particularly effective for low-rise buildings, while its effectiveness for medium- and highrise buildings should be verified enlarging the range of investigated structures. Nevertheless, as highlighted by the results presented in this work, it is expected that the effect due to the use of self-centring column base joints may disappear after a certain limit number of storeys.

Finally, component fragility curves are derived based on the maximum interstorey drifts thresholds identified in Section 3.4 and reported in Table 5. The fragility curves for the different components and the different performance levels are shown in Figure 17(a) and (b) respectively for the MRF and MRF-CB. From the results, it is possible to observe how the introduction of the CBs does not produce any detrimental effect on the components and on the sequence of activation of the different mechanisms within the structure. The beams are the first to reach their elastic limit $\left(\mathrm{M}_{\mathrm{el}, \mathrm{b}}\right)$ and plastic $\left(\mathrm{M}_{\mathrm{pl}, \mathrm{b}}\right)$ limits in both structures. This highlights that the introduction of the CBs does not protect the beams from yielding, as expected from the design. Following the yielding of the beams, the friction devices in the CBs are successively activated. For the beams of both structures, two inelastic deformation levels are expressed in terms of the plastic rotation as a multiple of the chord rotation at yielding $\left(\theta_{\mathrm{y}, \mathrm{b}}\right)$. Then, the ultimate chord rotation is reached in the beams of both structures $\left(\theta_{\mathrm{u}, \mathrm{b}}\right)$. Additionally, the yielding of the columns of the first storey is reached $\left(\mathrm{M}_{\mathrm{pl}, \mathrm{c}}\right)$ for the MRF, as expected from the design, while the columns of the first storey of the MRF-CB do not undergo any damage, due to the presence of the CBs which fully protect the columns from yielding and the PT bars which do not experience yielding ( $\left.\mathrm{PT}_{\text {bars }}\right)$.

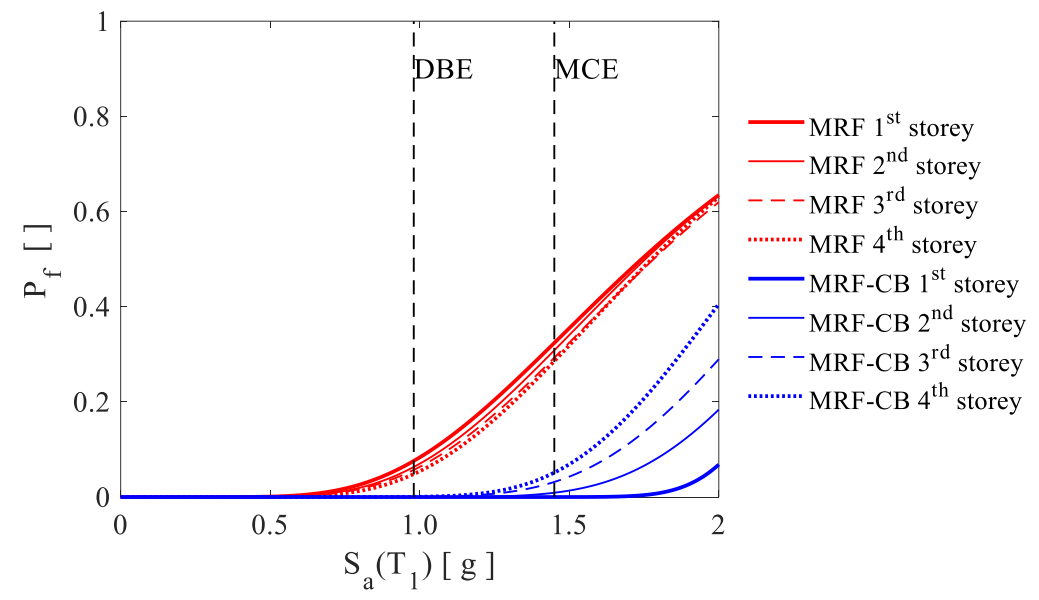

Figure 16-Comparison of fragility curves for repairability.

Table 6-Probability of failure for the repairability based on residual interstorey drifts.

\begin{tabular}{cccc}
\hline & Probability of failure & DBE & MCE \\
\hline \multirow{3}{*}{ MRF } & $1^{\text {st }}$ storey & $7.6 \%$ & $32 \%$ \\
& $2^{\text {st }}$ storey & $6.3 \%$ & $31 \%$ \\
& $3^{\text {st }}$ storey & $5.6 \%$ & $29 \%$ \\
& $4^{\text {st }}$ storey & $4.8 \%$ & $28 \%$ \\
\hline \multirow{3}{*}{ MRF-CB } & $1^{\text {st }}$ storey & $0 \%$ & $0 \%$ \\
& $2^{\text {st }}$ storey & $0 \%$ & $1.0 \%$ \\
& $3^{\text {st }}$ storey & $0.2 \%$ & $3.0 \%$ \\
& $4^{\text {st }}$ storey & $0.4 \%$ & $5.0 \%$ \\
\hline
\end{tabular}



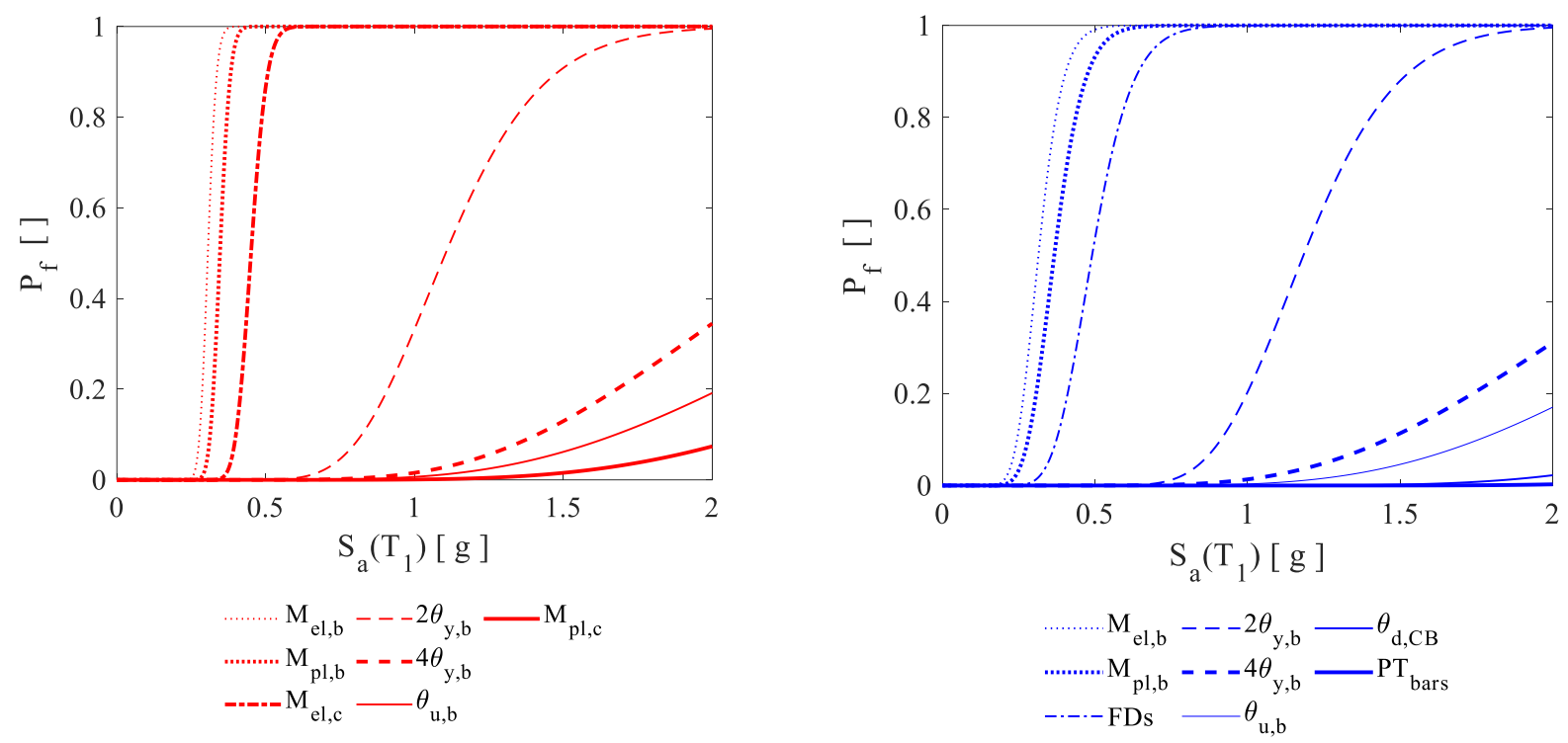

Figure 17-Components-level fragility curves for (a) MRF and (b) MRF-CB.

\section{CONCLUSIONS}

This work investigates the behaviour of an innovative connection which consists of a rocking column base where the seismic behaviour is controlled by a combination of friction devices that promote the energy dissipation and posttensioned bars with disk springs, introduced to provide self-centering capabilities. A design procedure of the connection is presented, a numerical model is defined in OpenSees and validated against experimental results. Incremental Dynamic Analyses are performed on a four-storey case study steel Moment Resisting Frame, including the hysteretic behaviour of the connection, to assess the seismic performance of the frame while also accounting for the record-to-record variability. Fragility curves are derived to evaluate the effectiveness of the proposed column base connections in reducing residual drifts and in protecting the first-storey columns from damage. The following conclusions are drawn: 1) The self-centring behaviour of the column bases results as an effective measure in limiting the residual drifts of the structure, under both the design basis and the maximum credible earthquake intensities; 2) The first storey columns are fully protected from yielding, providing significant advantages in terms of repairability, and hence resilience of the structure; 3) The introduction of the column bases does not produce any detrimental effect on the peak values of the seismic demands in terms of global and components based engineering demand parameters. Hence, the hierarchy of activation of the several mechanisms within the structure is the same for both the considered frames; 4) The use of a self-centring system localised only in the column bases is very effective for re-centring low-rise buildings, while its effectiveness for medium-and highrise buildings may be not enough. In fact, the self-centring effect in a Moment Resisting Frame due to the adoption of self-centring column base joints tends to reduce for an increasing number of storeys.

\section{REFERENCES}

1 EN 1998-1, Eurocode 8: Design of structures for earthquake resistance - Part 1: General rules, seismic actions and rules for buildings, 2004, European Committee for Standardization, Brussels.

2 ASCE/SEI 7-16. Minimum design loads and associated criteria for buildings and other structures, American Society of Civil Engineers, 2017, Reston, USA.

3 ANSI/AISC 341-16 Seismic provisions for structural steel buildings, American Institute of Steel Construction, 2016, Chicago, USA.

4 M. Latour, G. Rizzano, Full strength design of column base connections accounting for random material variability, Eng. Struct. 48 (2013) 458-71.

5 M. D'Aniello, R. Tartaglia, S. Costanzo, R. Landolfo, Seismic design of extended stiffened end-plate joints in the framework of Eurocodes, J. Constr. Steel Res. 128 (2017) 512-27.

6 R. Tartaglia, M. D’Aniello, G.A. Rassati, J.A. Swanson, R. Landolfo, Full strength extended stiffened end-plate joints: AISC vs recent European design criteria, Eng. Struct. 159 (2018) 155-71

7 R. Tartaglia, M. D'Aniello, M. Zimbru, R. Landolfo, Finite element simulations on the ultimate response of extended stiffened end-plate joints. Steel and Composite Structures, An International Journal 27(6) (2018) 727-745. DOI: $10.12989 /$ scs.2018.27.6.727

8 T.T. Soong, Jr B.F. Spencer, Supplemental energy dissipation: state-of-the-art and state-of-the practise, Eng. Struct. 24(3) (2002) 243-259.

9 S. Symans, F.A. Charney, A.S. Whittaker, M.C. Constantinou, C.A. Kircher, M.W. Johnson, R.J. McNamara, Energy Dissipation Systems for Seismic Applications: Current Practice and Recent Developments, J. Struct. Eng. 134(1) 
(2008) 3-21.

10 C.E. Grigorian, T.S. Yang, E.P. Popov, Slotted bolted connection energy dissipators, Earthq. Spectra 9(3) (1993) 491-504.

11 G.C. Clifton, J.W. Butterworth, Moment-resisting steel framed seismic-resisting systems with semi-rigid connections, 12 ${ }^{\text {th }}$ World Conf. on Earthq. Eng. 30 Jan -17 Feb, 1993, Auckland, New Zealand.

12 FREEDAM: FREE from DAMage steel connections, 2015-2018, Final report, Fund for Coal and Steel Grant Agreement No. RFSR-CT-2015-00022.

13 M. Latour, V. Piluso, G. Rizzano, Experimental analysis of beam-to-column joints equipped with sprayed aluminium friction dampers, J. Constr. Steel Res. 146 (2018) 33-48.

14 J. Erochko, C. Christopoulos, R. Tremblay, H. Choi, Residual drift response of SMRFs and BRB frames in steel buildings designed according to ASCE 7-05, J. Struct. Eng. 137 (5) (2010) 589-599.

15 J. Ricles, R. Sause, M. Garlock, C. Zhao, Posttensioned Seismic-Resistant Connections for Steel Frames, J. Struct. Eng. 127(2) (2001) 113-121.

16 C. Christopoulos, A. Filiatrault, C-M. Uang, B. Folz, Posttensioned energy dissipating connections for momentresisting steel frames, J. Struct. Eng. 128(9) (2002) 1111-20.

17 P. Rojas, J.M. Ricles, R. Sause, Seismic performance of post-tensioned steel moment resisting frames with friction devices, J. Struct. Eng. 131(4) (2005) 529-40.

18 H.J. Kim, C. Christopoulos, Friction damped posttensioned self-centering steel moment-resisting frames, J. Struct. Eng. 134(11) (2008) 1768-79.

19 G. MacRae, G.C. Clifton, Low Damage Design of Steel Structures, Steel Innovations 2013 Workshop, Christchurch, 21-22 Feb. 2013, New Zealand.

20 N.B. Chancellor, M.R. Eatherton, D.A. Roke, T. Akbas, Self-Centering Seismic Lateral Force Resisting Systems: High Performance Structures for the City of Tomorrow, Buildings 4 (2014) 520-548.

21 M. Latour, G. Rizzano, A theoretical model for predicting the rotational capacity of steel base joints, Eng. Struct. 91 (2013) 89-99.

22 P.T. Rodas, F. Zareian, A. Kanvinde, Hysteretic model for exposed column-base connections, J. Struct. Eng.; 142 (12) (2016) 1-14.

23 T. Takamatsu, H. Tamai, Non-slip-type restoring force characteristics of an exposed-type CB, J. Constr. Steel Res. 61(7) (2005) 942-961.

24 M. Ikenaga, T. Nagae, M. Nakashima, K. Suita, Development of CBs having self-centering and damping capability. $5^{\text {th }}$ Int. Conf. on Behaviour of Steel Struct. in Seismic Areas 2006, Yokohama, Japan.

25 J.M. Fischer, L.A. Kloiber, Base Plate and Anchor Rod Design. American Institute of Steel Construction, 2006, Chicago, USA.

26 H. Mackinven, G.A. MacRae, S. Pampanin, G.C. Clifton, J. Butterworth, Generation four steel moment frame joints. $8^{\text {th }}$ Pacific Conf. on Earthq. Eng. 2007 Singapore.

27 C.C. Chou, J.H. Chen, Analytical model validation and influence of CBs for seismic responses of steel post-tensioned self-centering MRF systems. Eng. Struct. 33(9) (2011) 2628-2643.

28 H. Chi, J. Liu, Seismic behaviour of post-tensioned CB for steel self-centering moment resisting frame, J. Constr. Steel Res. 78 (2012) 117-130.

29 T. Yamanishi, K. Kasai, T. Takamatsu, H. Tamai, Innovative column-base details capable of tuning rigidity and strength for low to medium-rise steel structures. $15^{\text {th }}$ World Conf. on Earthq. Eng. 2012, Lisbon, Portugal.

30 G.A. MacRae, C.R. Urmson, W.R. Walpole, P. Moss, K. Hyde, G.C. Clifton, Axial Shortening of Steel Columns in Buildings Subjected to Earthquakes, B. of The New Zealand Society for Earthq. Eng. 42(4) (2009) 275-287.

31 J. Borzouie, G.A. MacRae, J.G. Chase, G.W. Rodgers, G.C. Clifton, Experimental studies on cyclic performance of CB strong axis - aligned asymmetric friction connections, J. Struct. Eng. (ASCE), 142(1) (2016) 1-10.

32 F. Freddi, C.A. Dimopoulos, T.L. Karavasilis, Rocking damage-free steel CB with Friction Devices: design procedure and numerical evaluation, Earthq. Eng. Struct. Dyn. 46 (2017) 2281-2300.

33 F. Freddi, C.A. Dimopoulos, T.L. Karavasilis, Experimental evaluation of a rocking damage-free steel CB with friction devices, J. Struct. Eng. (2020) ASCE, DOI: 10.1061/(ASCE)ST.1943-541X.0002779

34 V. Kamperidis, T.L. Karavasilis, G. Vasdravellis, Self-centering steel CB with metallic energy dissipation devices, J. Constr. Steel Res. 149 (2018) 14-30.

35 X.T. Wang, C.D. Xie, L.H. Lin, J. Li, Seismic behaviour of self-centering concrete-filled square steel tubular (CFST) CB. J. Constr. Steel Res. 156 (2019) 75-85.

36 M. Latour, G. Rizzano, A. Santiago, L. Da Silva, Experimental response of a low-yielding, self-centering, rocking CB joint with friction dampers, Soil Dyn. Earthq. Eng. 116 (2019) 580-592.

37 S. Mazzoni, F. McKenna, M.H. Scott, G.L. Fenves OpenSEES: Open System for earthquake engineering simulation, Pacific Earthquake Engineering Research Centre (PEER), 2009, Univ. of California, Berkley, CA, Available at: http://opensees.berkeley.edu.

38 D. Vamvatsikos, C.A. Cornell, Incremental Dynamic Analysis, Earthq. Eng. Struct. Dyn. 31(3) (2002) $491-514$.

39 O.S. Kwon, A. Elnashai, The effect of material and ground motion uncertainty on the seismic vulnerability curves of RC structure. Eng. Struct. 28(2) (2006) 289-303. DOI: 10.1016/j.engstruct.2005.07.010 
40 E. Tubaldi, M. Barbato, A. Dall'Asta, Influence of model parameter uncertainty on seismic transverse response and vulnerability of steel-concrete composite bridges with dual load path, J. Struct. Eng. 138(3) (2012) 363-374. DOI: 10.1061/(ASCE)ST.1943-541X.0000456

41 M. Shinozuka, M.Q. Feng, H-K Kim, S-H Kim, Nonlinear static procedure for fragility curve development, J. Eng. Mech. 126 (12) (2000) 1287-95.

42 J. McCormick, H. Aburano, M. Nakashima, Permissible residual deformation levels for building structures considering both safety and human elements, $14^{\text {th }}$ World Conf. Earthq. Eng. 12-17 Oct 2008, Beijing, China.

43 T. Rossetto, P. Gehl, S. Minas, C. Galasso, P. Duffour, J. Douglas, O. Cook O, FRACAS: A capacity spectrum approach for seismic fragility assessment including record-to-record variability. Eng. Struct. 125 (2016) 337-348.

44 F. Freddi, J.E. Padgett, A. Dall'Asta, Probabilistic seismic demand modeling of local level response parameters of an RC frame. B. Earthq. Eng. 15(1) (2017) 1-23.

45 F. Freddi, E. Tubaldi, L. Ragni, A. Dall'Asta, Probabilistic performance assessment of low ductility reinforced concrete frames retrofitted with dissipative braces, Earthq. Eng. Struct. Dyn. 42(7) (2013) 993-1011.

46 EN 1993-1-8, Eurocode 3: Design of steel structures, Part 1-8: Design of steel structure: General rules and rules for buildings, 2005, European Committee for Standardization, Brussels.

47 EN 1993-1-1, Eurocode 3: Design of steel structures, Part 1-1: Design of steel structures: Design of joints, 2005, European Committee for Standardization, Brussels.

48 G.F. Cavallaro, A. Francavilla, M. Latour, V. Piluso, G. Rizzano, Cyclic behaviour of friction materials for low yielding connections. Soil Dyn. Earthq. Eng. 114 (2018) 404-423.

49 M. D'Antimo, M. Latour, G.F. Cavallaro, J.P. Jaspart, S. Ramhormozian, J.F. Demonceau, Short- and long- term loss of pre-loading in slotted bolted connections. J. Constr. Steel Res. 167 (2020) 105956.

50 D. Lignos, H. Krawinkler, Deterioration Modelling of Steel Components in Support of Collapse Prediction of Steel Moment Frames under Earthquake loading, J. Struct. Eng. 137 (2011) 1291-1302

51 F. Charney, W. Downs, Modelling procedures for panel zone deformations in moment resisting frames. Connections in Steel Struct. V 2004. ESSC/AISC Workshop, Amsterdam.

52 H. El Jisr., E. Ahmed, D. Lignos, Hysteretic Behavior of Moment-Resisting Frames considering Slab Restraint and Framing Action, J. Struct. Eng. (2020) ASCE, DOI: 10.1061/(ASCE)ST.1943-541X.0002696.

53 I. Iervolino, C. Galasso, E. Cosenza, REXEL: Computer aided record selection for code-based seismic structural analysis, B. Earthq. Eng. 8 (2010) 339-362. 